\title{
THE LESS COMMON FORMS OF PULMONARY HYPERTENSION
}

\author{
BY \\ WILLIAM EVANS \\ From the Cardiac Department of the London Hospital \\ Received July 25, 1958
}

The circumstances in which pulmonary hypertension is found alone or in association with emphysema, mitral stenosis, or congenital cardiac shunts have been described already (Gilmour and Evans, 1946; Evans, 1951; Evans et al., 1957; Evans and Short, 1957 and 1958). This paper discusses pulmonary hypertension in relation to the less common clinical states that cause a rise in pulmonary arterial pressure: these include recurring pulmonary embolism, strangulation of pulmonary veins, myxoma of the left atrium, neoplasia, scleroderma, pneumoconiosis from anthracosis or asbestosis, and holo-hypertension.

Should pulmonary hypertension supervene on these several states, the symptoms common to the hypertension are uppermost and are seldom modified by the associated condition. In all of them, however, signs are added which help to uncover the disease that has either caused the hypertension or favoured its development.

\section{Recurring Pulmonary Embolism}

Case 1. A man, aged 63, had enjoyed good health until 18 months before when he noticed that while on holiday he was unable to climb hills as easily as before; on his return home he again became symptom-free. Six months later he was awakened by a severe stabbing pain in the back, which was aggravated by movement but not by breathing. There was an unproductive cough, but no fever or dyspnœe. Pleurisy was diagnosed and he recovered well after a few days in bed. Six months later he experienced epigastric pain after walking some 20 yards and it ceased quickly when he halted. There was also dyspncea on effort and he was admitted to hospital a little over a year after the onset of his symptoms. By this time the pain had lessened, but the breathlessness, which was never of the paroxysmal kind, was worse and he could manage only one flight of stairs.

On examination there was slight cyanosis and cedema of both ankles. The jugular pulse showed a prominent atrial wave. The liver seemed slightly enlarged. Palpation of the heart showed nothing unusual, and no pulsation could be felt over the pulmonary artery where natural splitting of the second sound was heard, with accentuation of its pulmonary component. The systemic blood pressure was somewhat raised and the following figures were recorded in hospital-190/140,160/125, 170/130,140/110, 160/125, and 140/100. The blood count was normal. The cardiogram showed prominent $P$ waves and right ventricular preponderance (Fig. 1). Cardioscopy showed moderate enlargement of the right ventricle, and much dilatation of the pulmonary artery and both its branches (Fig. 4). The lung fields were abnormally clear except for a small shadow in one film on the right below the outer end of the horizontal fissure which probably indicated an old pulmonary infarct. Cardiac catheterization discovered no shunt; the pressure in the main pulmonary artery was $100 / 52$ and that in the right atrium, $12 / 0 \mathrm{~mm}$. $\mathrm{Hg}$. The mixed venous blood samples were approximately 45 per cent saturated.

Edema of the ankles and abdominal pain reappeared within a month of leaving hospital, and great dyspnœa and cyanosis followed even slight exertion, while triple heart rhythm from addition of the third heart sound was elicited for the first time. When re-admitted, it was found that although the atrial pulse in the neck was as prominent as ever the second heart sound in the pulmonary area was no longer loud. Four weeks later, after a sudden exacerbation of abdominal pain, the patient called for a bed pan, collapsed, and died twelve hours later. The illness had lasted 18 months; during that time there had never been hæmoptysis nor pain in the legs, and there was no evidence of varicose veins.

Necropsy findings. There was considerable enlargement of the heart which weighed $503 \mathrm{~g}$. (17 oz.), with great dilatation and moderate hypertrophy of both the right atrium and right ventricle whose conus was $0.8 \mathrm{~cm}$. thick. The left ventricle $(1.3 \mathrm{~cm}$. thick) was not dilated, and there was no cardiac infarction. All the valves were healthy. The coronary arteries showed rather severe atheroma and the lumen of the left coronary was reduced to pin-point diameter for a length of $4 \mathrm{~cm}$. The right atrium and both ventricles contained ante-mortem thrombus, and similar thrombus was found in a valve pocket in the right femoral vein. The customary signs of heart failure were observed in the liver and kidneys.

A laminated ante-mortem thrombus $(0.7 \mathrm{~cm}$. thick) was found adhering to the main left pulmonary artery, extending into the lingular artery, and occluding it; there was an old infarct in the adjacent lung tissue. An arteriogram 


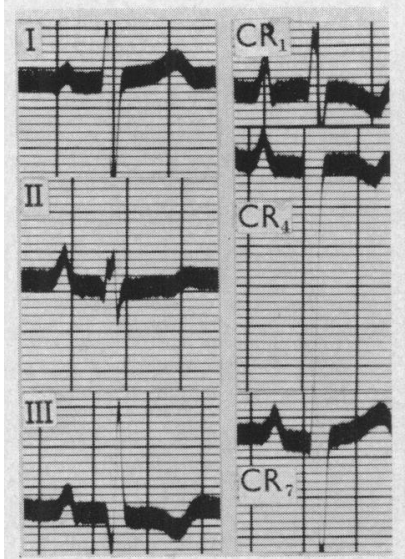

FIG. 1.-Pulmonary hypertension from recurring pulmonary embolism. Electrocardiogram shows right atrial and ventricular preponderance. Case 1.

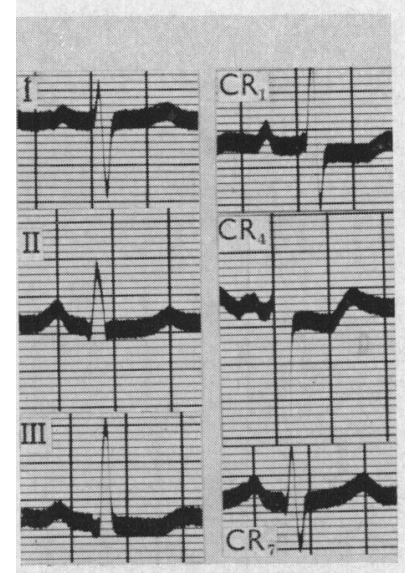

Fig. 2.-Pulmonary hypertension from recurring pulmonary embolism. Electrocardiogram shows right ventricular and slight right atrial preponderance. Case 2.

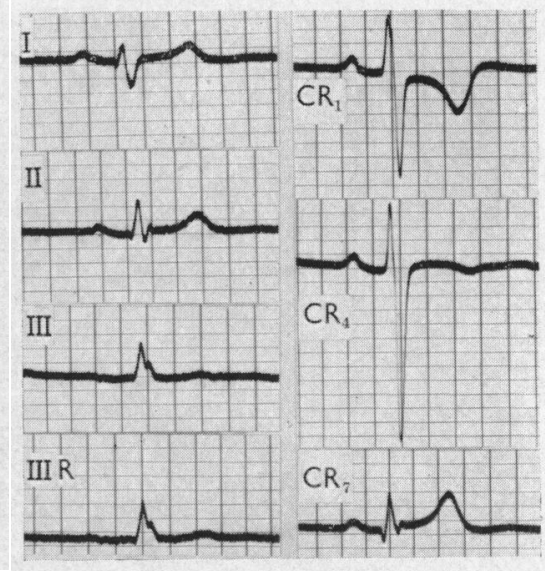

FIG. 3.-Strangulation of pulmonary veins. Electrocardiogram shows right ventricular duress, but short of frank preponderance. Thus, the $T$ wave is upright in leads II and III, and the $S$ wave is greater than $R$ in CR1. Case 3.

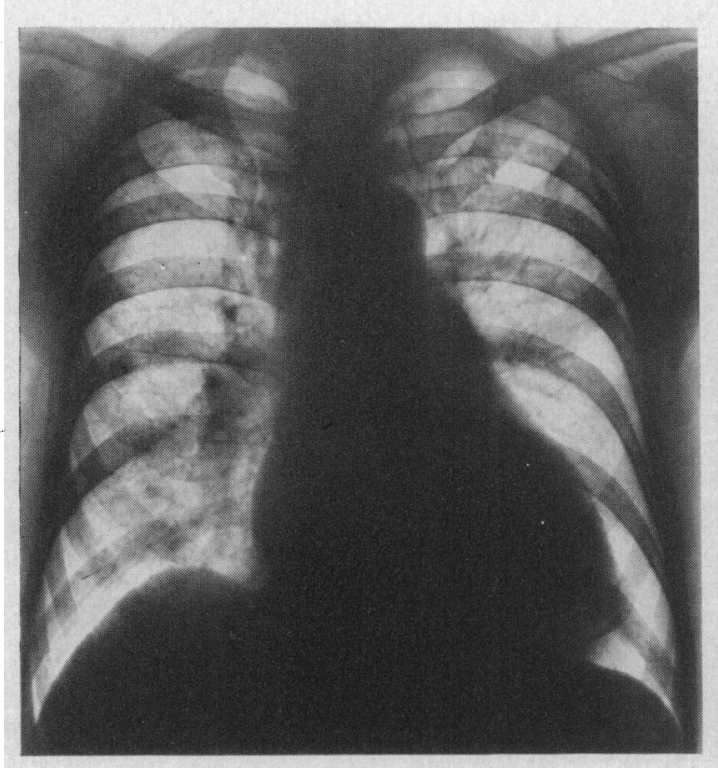

FIG. 4.-Pulmonary hypertension from recurring pulmonary embolism. Prominence of the pulmonary artery and its primary branches, some of which show abnormal density. Periphery of lung fields clear. Case 1.

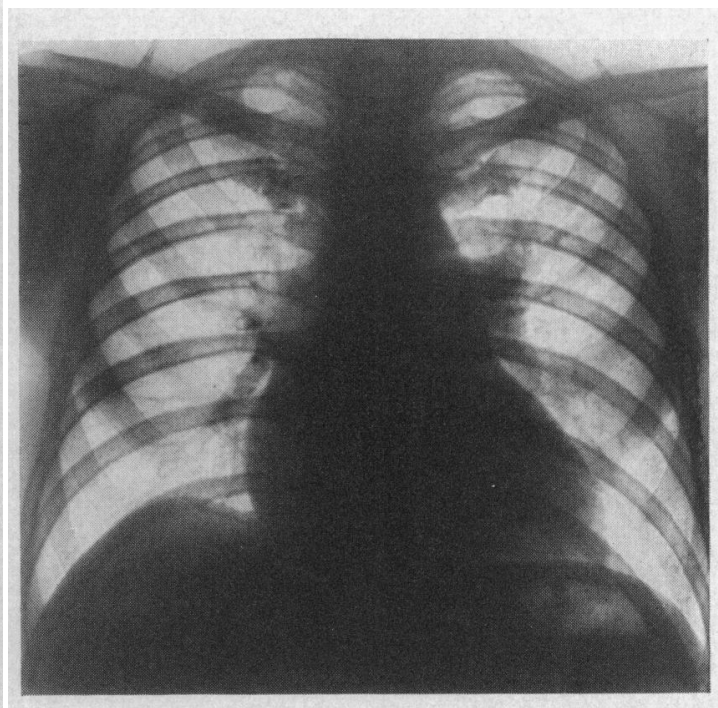

FIG. 5.-Pulmonary hypertension from recurring pulmonary embolism. Enlargement of right atrium, right ventricle, pulmonary artery and its primary branches. Unusual density of some pulmonary arteries. Exceptionally clear outlying lung fields. Case 2. 
could not be performed on the right lung on account of occlusion of the main artery by a laminated and firmly adherent ante-mortem thrombus which extended for $6 \mathrm{~cm}$. from the hilum, blocking many of the branches to each lobe. There were three small infarcts in this lung. A bronchial arteriogram demonstrated a much greater diameter than normal for the arteries to the right lung, and the arborization was correspondingly more profuse than in the left lung. A pulmonary arteriogram of the left lung showed dilatation of the main artery, but its branches showed a normal calibre. Five large filling defects corresponded with the sites of thrombotic occlusion; over two of these areas abnormal subpleural arteries formed an anastomosis between two branches of the pulmonary arterial tree.

On microscopical examination of the lungs the small elastic arteries were frequently occluded by a thrombus which had become canalized; such recanalization usually appeared as a single channel, but sometimes there were as many as four channels. Many of the elastic arteries, especially those in the left lung, were healthy. The small muscular arteries in some parts of the lungs were also healthy, but in many the lumen was greatly reduced in size by recanalized thrombus. The majority of the arterioles were healthy and only once was there narrowing from recanalization of an occluding thrombus.

There was no evidence anywhere of either medial hypertrophy or hypoplasia or of intimal proliferation.

Case 2. A man, aged 38, had been rejected for military service by a Medical Board 13 years before on account of varicose veins; nothing was said about his heart at this time. During the next eight years he suffered from recurrent ulceration of the right leg and eczema of both ankles. At the age of 33 a Trendelenberg operation was performed on both legs, and three years later he experienced pain across the chest while walking; despite great difficulty in breathing he arrived home unaided, but he had to halt frequently on the way. The chest pain ceased after three hours, but some tightness persisted for several days and he was unable to return to work for three weeks. During the following months there was progressive dyspnœa which compelled him to give up work a year later. Mercurial injections were prescribed for his odema.

A loud systolic murmur in the left fourth intercostal space near the sternum at this time suggested the diagnosis of ventricular septal defect. Six months later he was admitted to hospital when he was found to be short of breath after walking slowly the length of the ward. He also suffered from nocturnal dyspnœa when each attack lasted about ten minutes. There was no cough, hæmoptysis, or chest pain. There was obvious cyanosis of the ears and face, solid œdema of both ankles, enlargement of the liver, and ascites. The blood count was normal. The external jugular veins were distended and a prominent atrial pulse was present. The radial pulse was small and the blood pressure was $120 / 95$. The cardiac impulse was diffuse and its character suggested right ventricular enlargement. A moderately loud systolic murmur at the left sternal border was not accompanied by a thrill. The second heart sound in the pulmonary area was loud and showed narrow splitting, while a triple rhythm was heard from addition of the third heart sound at the lower end of the sternum. The cardiogram showed right ventricular preponderance (Fig. 2). Cardioscopy demonstrated slight to moderate cardiac enlargement affecting chiefly the right ventricle and atrium. The pulmonary artery and both its branches were dilated, and the increased density of the left pulmonary artery was a special feature of the left oblique position (Fig. 5). In a film the medium branches were reduced to mere threads and the lung fields appeared exceptionally translucent. There was no evidence of pulmonary infarction.

A diagnosis of pulmonary hypertension was made and cardiac catheterization was considered advisable because it seemed likely that a congenital heart defect was also present, but the test had to be abandoned after inadvertent entry of the catheter into the coronary sinus. Throughout his stay in hospital the patient complained of tightness in the chest, and on one occasion it became severe on the right side and appeared to have its source in the pleura. He died three weeks later and two years after the first episode of tightness in the chest.

Necropsy findings. There was great enlargement of the heart which weighed $595 \mathrm{~g}$. (21 oz.) with moderate hypertrophy of the right atrium and very great hypertrophy of the right ventricle $(0.9 \mathrm{~cm}$. thick). There was no enlargement of the left atrium and left ventricle $(1.0 \mathrm{~cm}$. thick). The heart valves and the coronary arteries were healthy, and the heart septa were intact. Recent and old laminated ante-mortem thrombus was found in the right atrium, and there was complete thrombotic occlusion, apparently of long duration, of the left femoral vein $7 \mathrm{~cm}$. above the popliteal space. The usual signs of heart failure were present in the liver and spleen together with considerable ascites and small pleural effusions. A pulmonary arteriogram could not be carried out on account of thrombosis within the main pulmonary artery and both its branches. Partly organized thrombus almost wholly occluded both the right and the left pulmonary artery beginning $3 \mathrm{~cm}$. beyond the pulmonary valve and extending into many peripheral branches.

On microscopical examination of the lungs a few small elastic arteries demonstrated some degree of hypertrophy and many showed old thrombosis with canalization producing a lumen of variable size and often very narrow (Fig. 6A). The muscular arteries sometimes showed contracture and without thrombosis, while others demonstrated old and recent thrombosis which in places had produced complete occlusion of the lumen and elsewhere partial obstruction, in that recanalization had taken place. There was no evidence of medial hypoplasia (Fig. 6B). The arterioles were usually normal, but occasionally they were narrowed by adherent thrombus.

Discussion. We have stated elsewhere (Evans et al., 1957) that pulmonary hypertension following repeated pulmonary embolism may be difficult to distinguish on clinical grounds from solitary pulmonary hypertension, and that this may apply even at necropsy, especially when the small arteries are involved. Furthermore, in all forms of pulmonary hypertension, thrombotic or even embolic occlusion of the larger pulmonary arteries is common, and only careful examination of the whole pulmonary arterial system can decide the primary condition.

In regard to the recognition of recurring embolism as the cause of pulmonary hypertension it is clear that clinical examination too often fails to arrive at this diagnosis, while examination at necropsy errs in its too frequent diagnosis. 

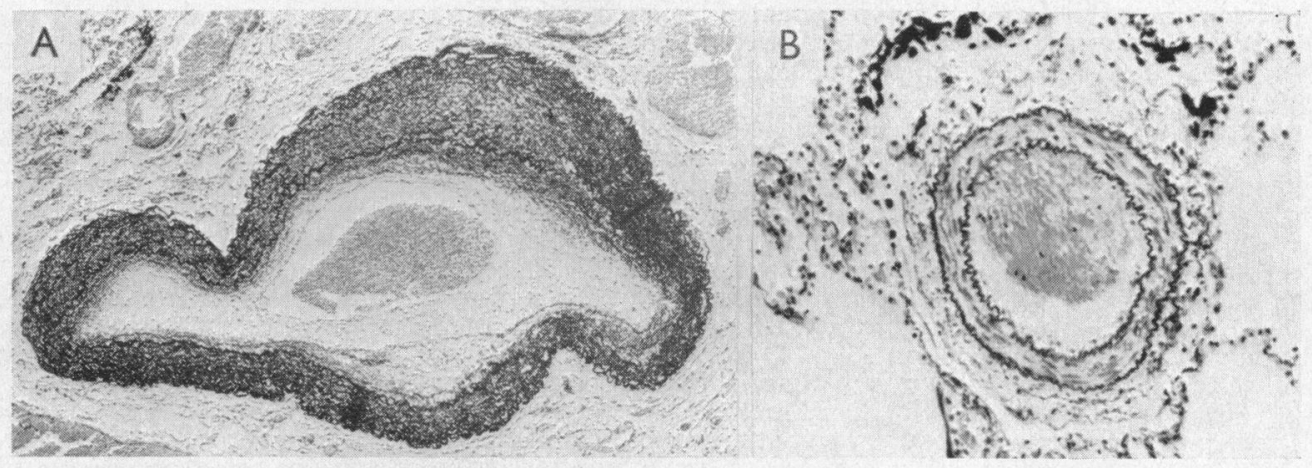

FIG. 6.-Pulmonary hypertension from recurring pulmonary embolism. (A) Elastic artery $(\times 33)$ shows hypertrophy of its wall and great lessening of its lumen by organizing thrombus. (B) Organizing thrombus within muscular artery $(\times 100)$ with intact media. Case 2.

Its clinical diagnosis is facilitated by attention to the following features. Pulmonary hypertension from recurring embolism tends to appear at a later age, usually over 40 , than the solitary form; episodes of pleuritic pain, breathlessness, hæmoptysis, and even the formation of pleural effusion, may occur; the electrocardiogram subsequent to such recurrences of pulmonary infarction changes from a pattern of right ventricular duress to one of frank preponderance; careful examination of the lower limbs may uncover swelling of one ankle in excess of the other, and evidence of varicose veins or of phlebothrombosis; terminally when thrombosis within the pulmonary artery has extended proximally to reach the pulmonary valves, the previous accentuation of the pulmonary second sound disappears; at cardioscopy one or other pulmonary artery commonly shows an

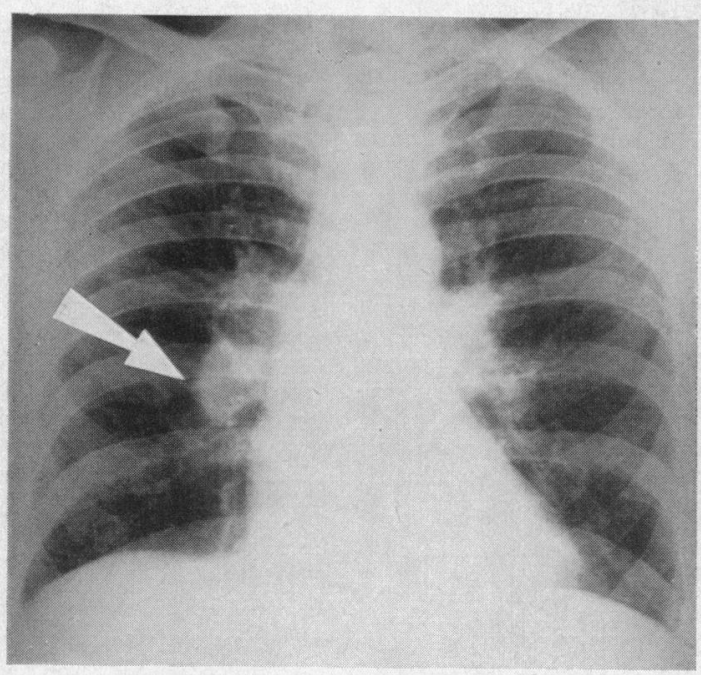

FIG. 7.-Pulmonary hypertension from recent pulmonary embolism. Unusual density of pulmonary arteries from an intra-arterial thrombus. Distal end of thrombus (arrow) marked by amputation of the arterial shadow. Patient was one outside this series.

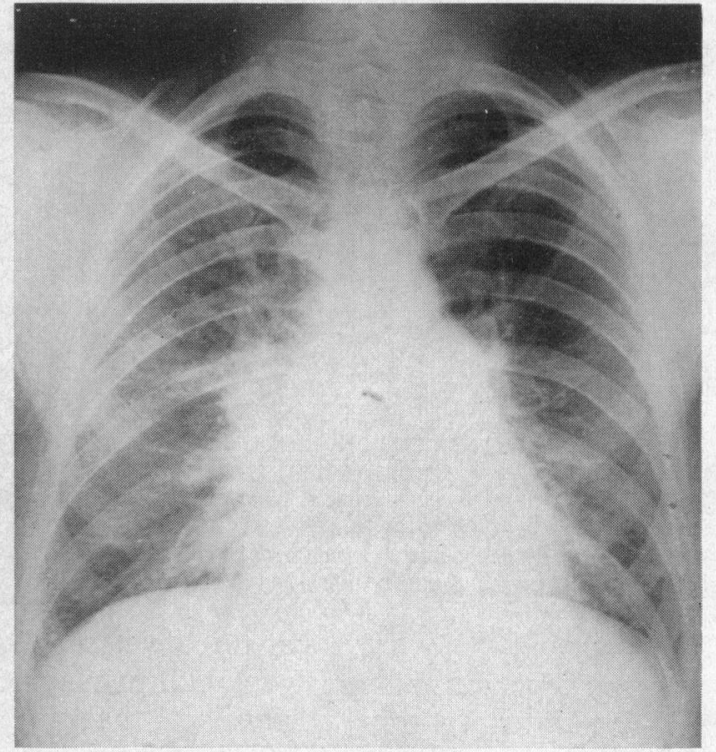

FIG. 8.-Strangulation of pulmonary veins. Moderate enlargement of pulmonary artery and prominent shadowing at hila. Case 3. 
increase in its density, a noticeable immobility, and abrupt amputation of its shadow at the site where the thrombus ends (Fig. 7).

In regard to treatment it would appear desirable to ligature the inferior vena cava to prevent the passage of further emboli from the veins of the lower extremities. To achieve this favourable end, however, is difficult. Thus, when pulmonary infarction, even if recurrent, does not initiate pulmonary hypertension, ligature is not needed, and when pulmonary hypertension has ensued, the purpose of the ligature no longer prevails.

\section{Strangulation of Pulmonary Veins}

Case 3. A man, aged 35, had been accepted for military service, and had participated actively in routine dutie until his discharge after four years on account of breathlessness which was considered to arise from mitral stenosis. This symptom continued for seven years when hæmoptysis took place, which a year later was so frequent and profuse as to need intravenous iron therapy.

When examined in hospital there was no breathlessness at rest. He was pale and slightly anæmic. His cough had abated and so also had hæmoptysis. His sputum did not contain tubercle bacilli and the Mantoux test was negative. Similarly, other serological tests were normal. The pulse was rather small and the blood pressure was $110 / 85$. The atrial pulse in the neck was a little prominent. There was pulsation over the right ventricle and its conus. Closure of the pulmonary valves was felt. In the pulmonary area there was a systolic murmur, which followed a sound in early systole, and close splitting of the second heart sound whose pulmonary component was exceptionally loud. No diastolic murmur was heard.

The electrocardiogram showed inversion of the $T$ wave in right ventricular leads as far as CR4, but the $R$ wave remained less than the $S$ wave in CR1 throughout the illness, while the T was upright in leads II and III; the P waves were natural (Fig. 3). Cardioscopy showed fullness of the right atrium, enlargement of the pulmonary artery, absence of left atrial enlargement, and heavy shadows at the pulmonary hila (Fig. 8). On cardiac catheterization the pulmonary arterial pressure was $95 / 40$ with a mean value of $60 \mathrm{~mm}$. At bronchoscopy the mucosa was found to be red and odematous, and it bled when touched.

He was treated in turn with streptomycin, prednisone, and deep X-rays, but he deteriorated when hæmoptysis recurred, and he died 12 years after the onset of breathlessness that gave rise to a diagnosis of heart trouble, and five years after the onset of hæmoptysis.

Necropsy findings. There was moderate hypertrophy without dilatation of the right ventricle $(1 \mathrm{~cm}$. thick); left ventricle $(1.7 \mathrm{~cm}$. thick). The endocardium, valves, and coronary arteries were healthy.

A grey firm mass, approximately $6 \mathrm{~cm}$. diam., situated at the tracheal bifurcation (Fig. 10), had produced stenosis of both main bronchi, and of the pulmonary arteries to the right middle and lower lobes. It closely embraced the pulmonary veins, completely obliterating the lower right and the upper left veins, and severely constricting the two remaining pulmonary veins. Histological examination showed a dense hyaline fibrosis with scattered foci of plasma cells and lymphocytes mainly towards the periphery. The exact ætiology of the granulomatous process was unknown, but it did not seem to be tuberculous in nature, and two caseous glands that it enclosed were considered to be incidental.

Histological examination of the lungs showed gross distension of pulmonary veins which were either partly, but more often wholly, filled by organizing thrombus. Thrombus also lined portions of the larger pulmonary arteries. The lesser pulmonary arteries were contracted, but were unaffected by intimal proliferation, and their media was intact, for hypoplasia was absent (Fig. 9).

Discussion. Kunkel et al. (1954) reported 16 cases in which a mediastinal granuloma was confirmed following thoracotomy. In 11 the lesion was cystic and calcification was common, and as a rule it was situated to the right of the trachea. There was never proof that it was tuberculous in nature. Usually the patients had no symptoms, and the condition had been discovered following a radiological examination of the chest. It is unlikely that the case reported here is kindred to the cases described by these authors.

In 1951, however, Edwards and Burchell reported an identical case. This was a woman aged 26, who died following catheterization: she had complained of a cough for four years, but had voided no sputum and had no hæmoptysis, though latterly she had been troubled with great breathlessness. At necropsy a mass, which on microscopical examination showed dense bundles of relatively acellular collagen, had caused severe obstruction of the pulmonary veins. Thus, the left superior and inferior veins had joined to form a common trunk that was constricted to a diameter of $2 \mathrm{~mm}$. Similarly, the right superior pulmonary vein was reduced to $1 \mathrm{~mm}$. diameter. The right inferior vein was only moderately compressed.

Although the pulmonary artery pressure was $98 / 45$ and the authors reported the case under the title of multiple pulmonary venous obstruction with pulmonary hypertension, it does not comply with the definition which we have laid down for pulmonary hypertension (Evans et al., 1957), for the 


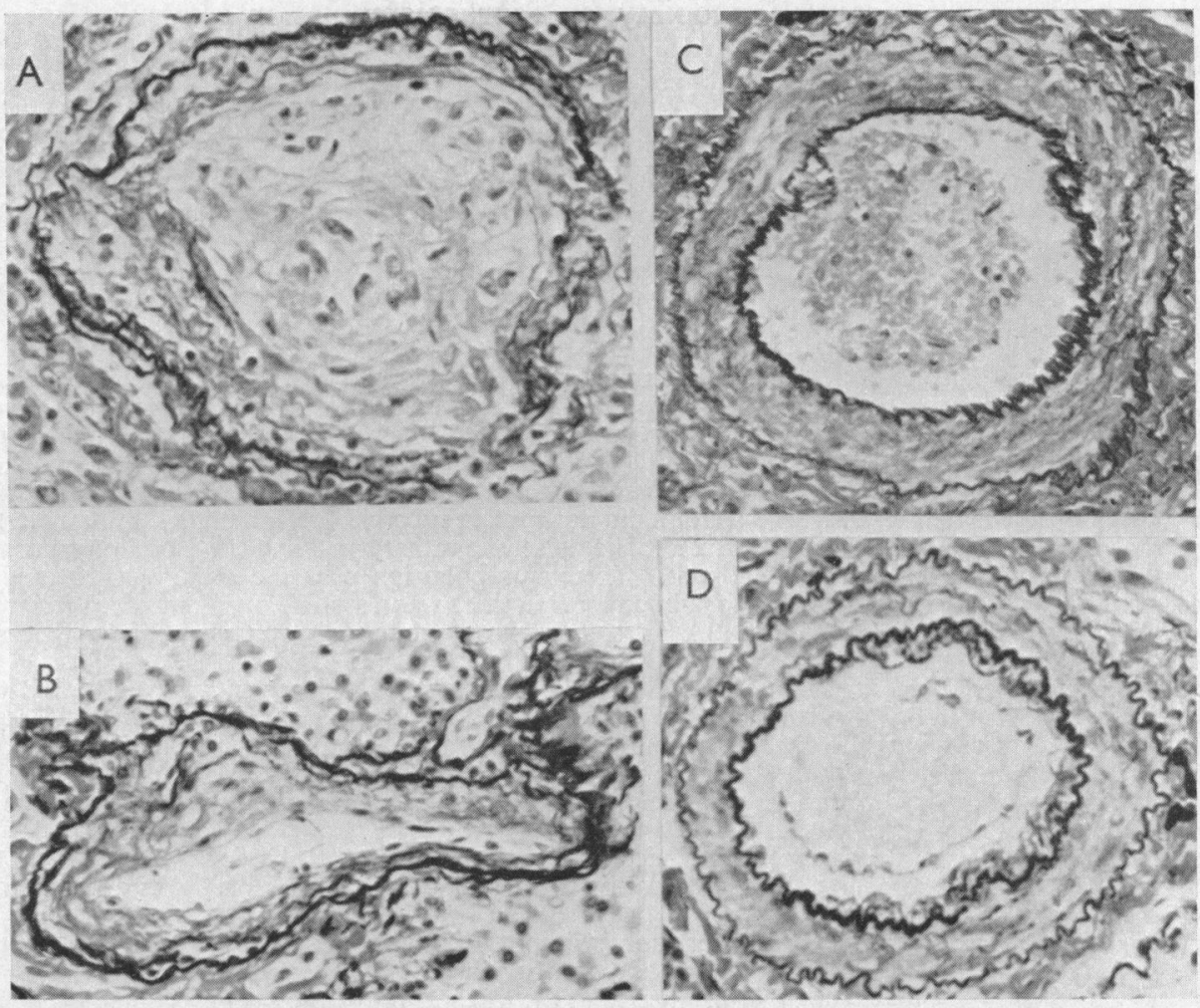

FIG. 9.-Strangulation of pulmonary veins. (A) Complete obliteration of pulmonary vein $(215 \mu)$ by organizing thrombus. (B) Partial obliteration of pulmonary vein $(85 \mu)$ by organizing thrombus. (C) Thrombus in muscular artery $(220 \mu)$. (D) Obliteration of muscular artery $(170 \mu)$ by recent thrombus. The walls of both muscular arteries are intact. Case 3.

electrocardiogram showed no evidence of right heart preponderance; thus, the $\mathrm{R}$ wave was only $0.4 \mathrm{mv}$. and S was $1.2 \mathrm{mv}$. in lead V1. The right ventricle at necropsy measured 0.5 to $0.7 \mathrm{~cm}$. in thickness compared with $1 \cdot 1 \mathrm{~cm}$. for the left ventricle. In the histological illustrations there was venous thrombosis, and canalized thrombosis in a muscular artery which had an intact media.

Almost identical findings were met with in the case reported here, so that although the pulmonary arterial pressure had been substantially raised, and presumably for some years, the electrocardiogram showed evidence of right ventricular duress only, and no ventricular preponderance. It is considered that the reason for this lies with the absence of intimal proliferation within the pulmonary arteries. The arterial walls were intact and showed no hypoplasia of the media. These findings appear to confirm that such medial deficiencies, of congenital origin and provoking occlusive intimal proliferation, are the cause and not the result of pulmonary hypertension.

This conclusion has an important bearing on treatment, because removal of a greater part of the granuloma in these cases, difficult though the procedure would be, will release constriction of the pulmonary veins, and in turn relieve the pulmonary arterial tension, for only exceptionally will there be arterial obstruction from intimal proliferation.

\section{MyXoma of the Left Atrium}

Case 4. A youth, aged 19, had been accepted for military service a year before, but when examined two months later he was discharged because of a heart murmur which was considered to arise from mitral stenosis. Six months later he became short of breath and was found to have heart failure for which he received customary treatment. 
Hæmoptysis followed by a persistent cough and pyrexia, were considered to have stemmed from pulmonary infarction. He improved a little for a time, but was admitted to hospital three months later on account of an increase in his symptoms.

He was pale, anæmic, and breathless. The pulse was small and 105 a minute, and later in the illness it became irregular from auricular fibrillation. The blood pressure was 110/70. The jugular venous pulse reached to the angle of the jaw. The pulmonary second sound was a little loud. In the mitral area there was a systolic murmur from mitral incompetence and triple rhythm from addition of the third heart sound. In the tricuspid area a systolic murmur from tricuspid incompetence was better heard during inspiration. The liver was enlarged, and there was some ascites and cedema of the ankles. Jaundice followed further pulmonary embolism, and right-sided hydrothorax developed. The cardiogram (Fig. 11) showed bifid $\mathbf{P}$ waves and evidence of right ventricular duress, but short of preponderance; later the tracing showed auricular fibrillation. Radiological examination showed enlargement of the heart to the right and left (Fig. 12), and prominence only of the left atrium. The sedimentation rate was raised consistently, varying from 37 to $97 \mathrm{~mm}$. an hour. The blood culture was sterile, and the hæmoglobin was 64 per cent. The white cell count was 9000 per c.mm. The serum albumen was $1.9 \mathrm{~g}$. and the globulin $4.5 \mathrm{~g}$. per $100 \mathrm{ml}$.

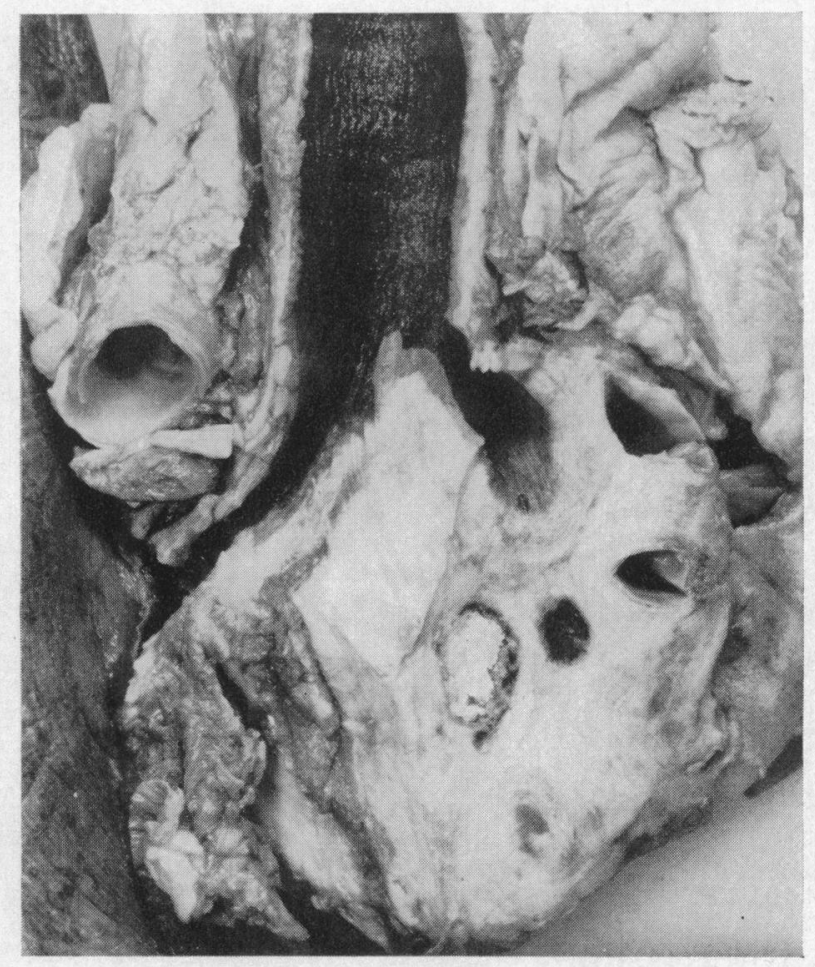

FIG. 10.-Mass at bifurcation of trachea is seen constricting bronchi, and tightly embracing two pulmonary veins with obliteraticn of the other two. Case 3.

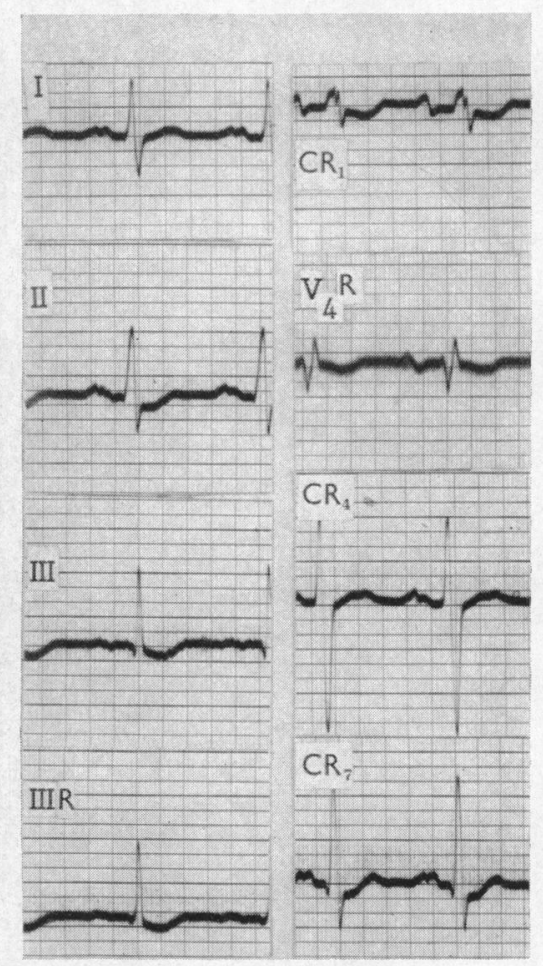

FIG. 11.-Myxoma of left atrium. Electrocardiogram shows right ventricular duress, but short of frank right heart preponderance. The S-T depression in most leads is a digitalis effect. Case 4.

The diagnosis was considered to be acute rheumatic endocarditis of both mitral and tricuspid valves in that there was evidence of considerable tricuspid incompetence and some mitral incompetence. He received routine treatment for heart failure and a blood transfusion was carried out. He improved a little and was about to leave hospital when he collapsed suddenly and died.

Necropsy findings. A myxomatous polyp $(6 \times 6 \times 3 \mathrm{~cm}$.) filled the left atrium and projected through the mitral valve into the left ventricle (Fig. 13). The heart weighed $529 \mathrm{~g} .\left(18 \frac{1}{2} \mathrm{oz}\right.$.). The left ventricle $(1 \mathrm{~cm}$. thick) was dilated, and the right ventricle $(0.8 \mathrm{~cm}$. thick) was hypertrophied. All valves were healthy. The customary signs of heart failure were present in other organs. The lungs showed large areas of infarction. Histological examination showed extensive thrombosis with recanalization of pulmonary veins (Fig.28 A), and similar uncanalized and recanalized thrombosis of a few large and small pulmonary arteries whose media was intact throughout, showing no segmental hypoplasia (Fig. 28B). 

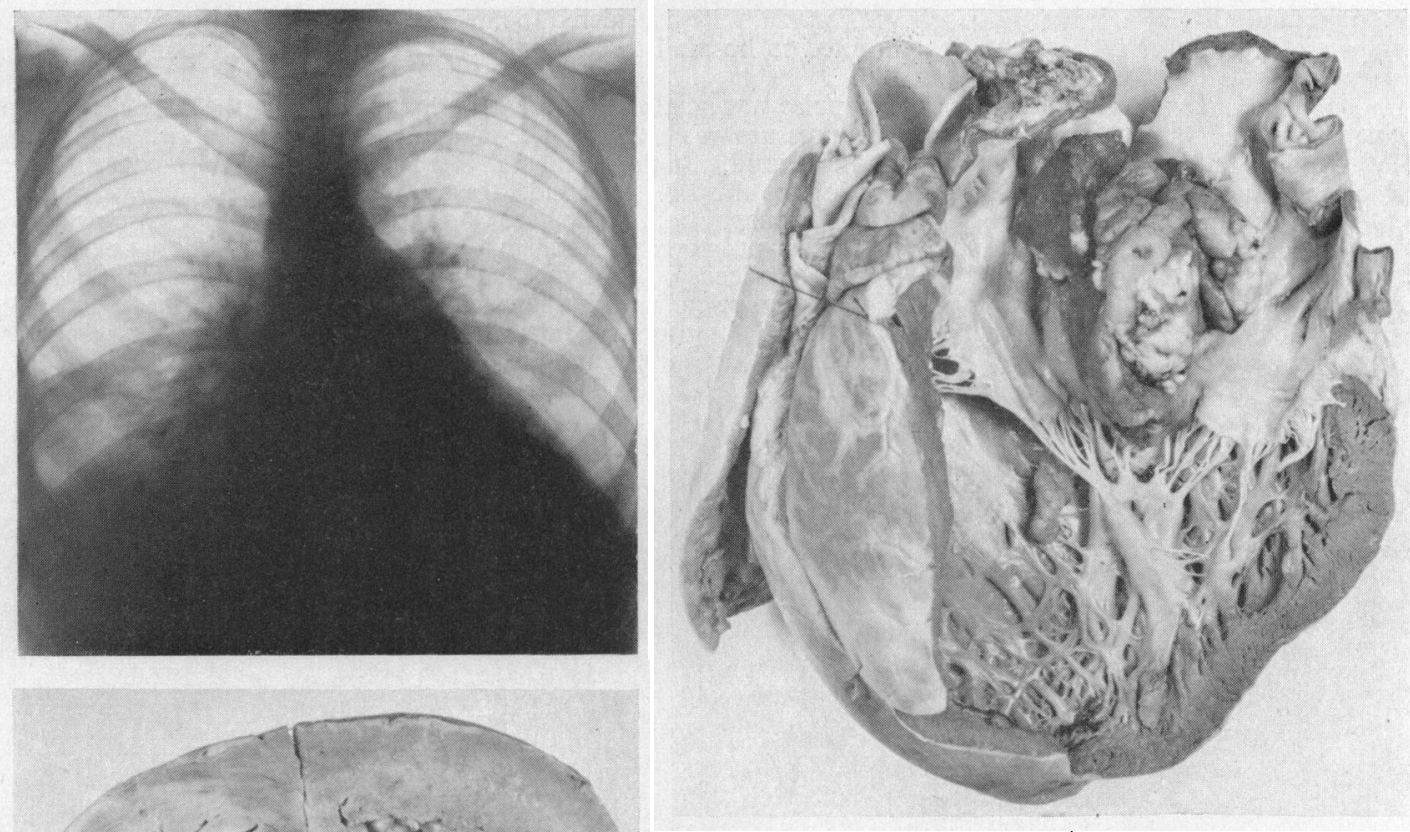

Case 5. A man, aged 59, was first seen because of loss of weight and energy; he had a mild fever and a raised sedimentation rate. The hæmoglobin content was 77 per cent, the white cell count 9000 per c.mm., the serum albumen was $2.7 \mathrm{~g}$. and serum globulin was $5.3 \mathrm{~g}$. He was watched for four years before he died. Other symptoms and signs were added during this period. Thus, breathlessness set in with palpitation, and signs of heart failure appeared. One time he experienced temporary blindness in one eye. The pulse was rather small and the blood pressure was usually about $140 / 85$ and later $90 / 60$. The jugular venous pressure was raised and an atrial pulse was noticed. The first heart sound was remarkably loud and followed by a moderate systolic murmur. The second heart sound was split in the pulmonary area and its pulmonary component was loud. Triple rhythm from addition of the third heart sound ultimately appeared. The pulmonary arterial pressure was $55 / 10 \mathrm{~mm}$. $\mathrm{Hg}$ and the right ventricular pressure $55 / 0$. The electrocardiogram showed no right ventricular preponderance, but some evidence of right ventricular duress latterly. Radiology of the chest showed enlargement of the right atrium and ventricle, some distension of the left atrium, and prominence of the pulmonary artery and its main branches. Ultimately his death was sudden.

Necropsy findings. A myxomatous growth filled the left atrium. There was moderate enlargement with hypertrophy of the right ventricle, and dilatation of the right atrium. The pulmonary artery was dilated and somewhat hypertrophied. Several areas of infarction were present in the lung. Microscopical examination showed contracted pulmonary arteries which here and there were partly filled with thrombus. There was no hypoplasia of the media, and no obstructive intimal proliferation.

Discussion. In the two patients just described, in whom a myxoma filled the left atrial cavity, there was evidence of a raised pulmonary arterial pressure or a state of pulmonary hypertonia, following obstruction of the blood flow from the lung to the heart. Although the condition, as judged from the symptoms, had been present for ten months in one and upwards of four years in the other, true pulmonary hypertension was not present, and the electrocardiogram showed only right ventricular duress, short of ventricular preponderance. This is explained by the absence of 
intimal proliferation within the pulmonary artery in spite of the raised pulmonary pressure. It is held that the absence of proliferation in this circumstance was directly related to the intact arterial walls, for neither case showed hypoplasia of the media. This again supports the view, that intimal proliferation seen in cases of pulmonary hypertension owes its inception to the medial deficiencies and not to the raised arterial pressure.

\section{NeOPLASIA}

Case 6. A man, aged 52, had complained of increasing breathlessness for four years, and had experienced bronchitis for several winters when much sputum was voided. Two months before, a right-sided hemiparesis took place with partial aphasia, but without loss of consciousness.

When examined in hospital he was breathless and had a bad cough. The pulse was natural and the blood pressure was $125 / 85$. The venous pulse in the neck was prominent, moist sounds were heard over both lung bases, the liver was enlarged, and there was œedema of the ankles. The second heart sound was closely split and its pulmonary component accentuated. Triple heart rhythm from addition of the third heart sound was heard before treatment commenced. The cardiogram showed gross right heart preponderance, and on cardioscopy there was moderate enlargement of the right atrium and ventricle, together with prominence of the main pulmonary artery and its primary branches.

He improved for a time from digitalization and the use of mercurial diuretics, but later he lost both appetite and weight, while the heart failure signs advanced in the face of treatment, and he died six months after his admission to hospital.

Necropsy findings. The heart weighed $460 \mathrm{~g}$., and showed great hypertrophy of the right ventricle whose wall was $0.9 \mathrm{~cm}$. thick compared with $1.7 \mathrm{~cm}$. in the case of the left ventricle. A carcinoma of the bronchus had spread to involve mediastinal glands and the pericardium. A pulmonary arteriogram showed large areas unfilled by injection mass because of obstructive arterial lesions. It also showed free pulmonary-bronchial anastomosis.

The growth had invaded the right pulmonary artery for a distance of $2 \mathrm{~cm}$. causing occlusive thrombosis of arteries to the right middle and lower lobe and to the left lower lobe. Hæmorrhagic infarction of the whole of the right middle lobe. Both lungs were emphysematous.

On microscopy the growth proved to be a polygonal cell carcinoma which had penetrated the wall of the main branches of each pulmonary artery in several places. Several arteries were occluded with intimal proliferation and organizing thrombus, which here and there was impregnated with neoplastic cells. Adjacent to the intimal proliferation were segments of arterial medial hypoplasia.

Case 7. A girl, aged 19, noticed a small lump in the lower part of her right thigh two years before. The diagnosis of an osteosarcoma of the femur was made and neither deep X-ray therapy nor implantation of radium checked its

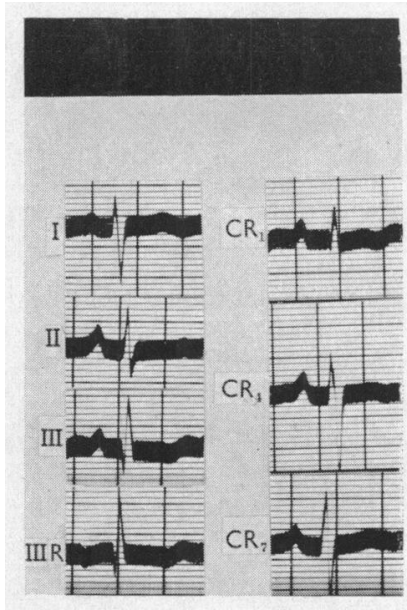

FIG. 15.-Pulmonary hypertension from pulmonary growth embolism. Electrocardiogram shows right ventricular preponderance, and moderate preponderance of right atrium. Case 7.
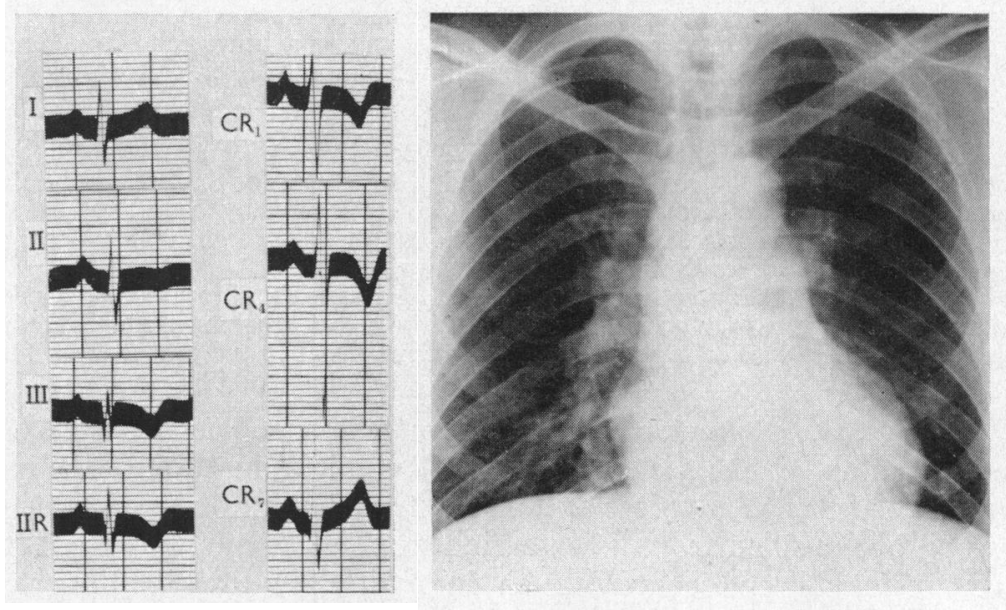

FIG. 16.-Pulmonary and systemic hypertension from scleroderma. Cardiogram shows right ventricular preponderance although $S$ is greater than $R$ in $C R 1$, and at necropsy there was great hypertrophy of the left ventricle as well as the right. Case 8.
Fig. 17.-Pulmonary and systemic hypertension from scleroderma. Enlargement of the right ventricle (determined in left oblique position), pulmonary artery and its branches, and of the left ventricle. Case 8. 
growth, and the leg was amputated. Five months before her death she developed a pleural effusion which resolved spontaneously on rest, but thereafter she complained of increasing shortness of breath.

The pulse was rapid and the blood pressure was 95/70. The atrial pulse was prominent in the neck. There, was increased pulsation over the right ventricle and its conus. A slight systolic murmur was audible to the left of the sternum as well as a triple heart rhythm from addition of the third heart sound, while in the pulmonary area the second heart sound was split with accentuation of its pulmonary component, and this was followed by a Graham Steell murmur. The cardiogram showed right atrial and right ventricular preponderance (Fig. 15). At cardioscopy, the right atrium, right ventricle and pulmonary artery with its primary branches were seen to be enlarged (Fig. 18).

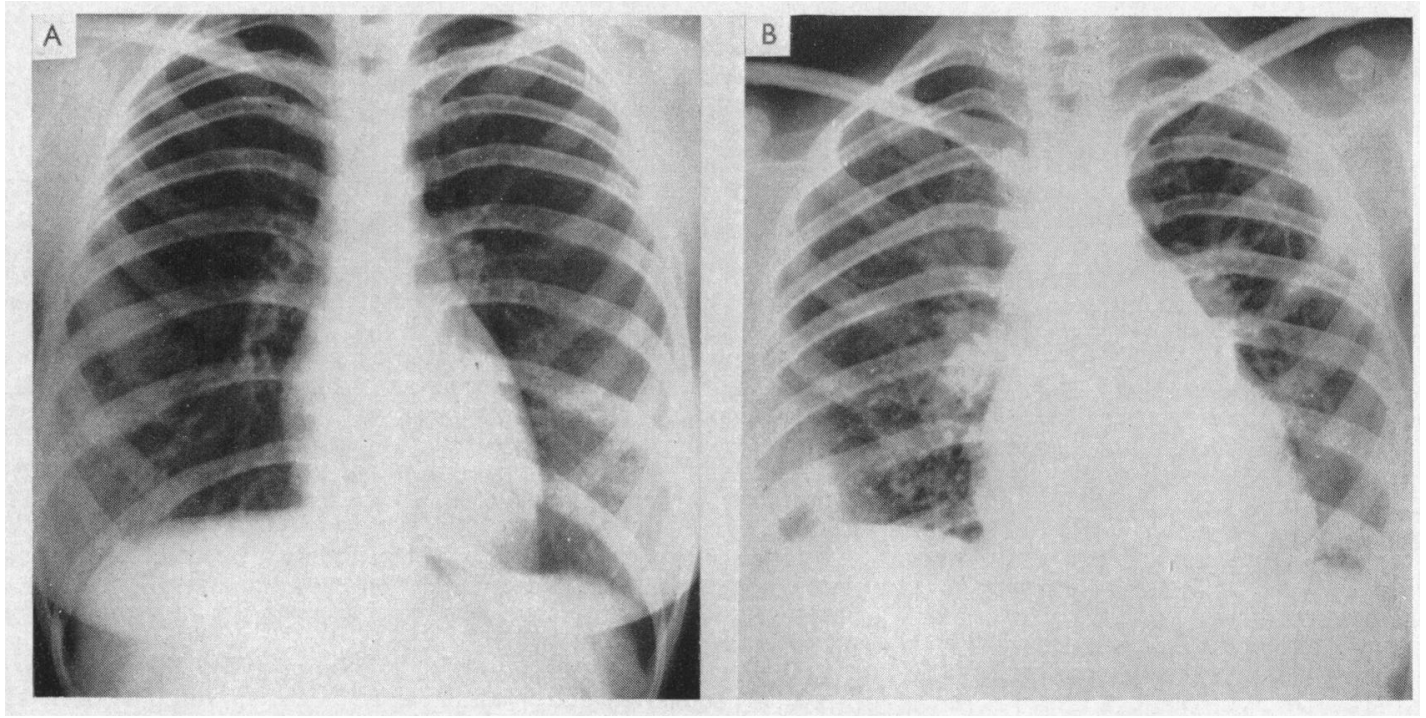

Fig. 18.-Pulmonary hypertension from pulmonary growth embolism. (A) Normal teleradiogram at start of illness. (B) Considerable enlargement of the right heart and of pulmonary artery and its branches with shadowing at both lung bases, found twelve months later. Case 7.

Necropsy findings. The heart weighed $234 \mathrm{~g}$. (10 oz.). There was dilatation and hypertrophy of the right ventricle with its wall $0.8 \mathrm{~cm}$. thick, compared with $1.3 \mathrm{~cm}$. for the left ventricle. The valves were healthy and there was no evidence of intracardiac thrombosis. Growth covered by thrombus filled both right and left pulmonary arteries and most of their primary branches except one supplying the right upper lobe. Several areas of infarction in lungs. No growth in lung parenchyma nor in mediastinal glands.

On microscopy the growth which was identified as a chondrosarcoma, filled most of the larger branches of the pulmonary artery, wholly occluding them, and in places breaking through the arterial wall to invade the surrounding tissue (Fig. 19). The lesser pulmonary arteries distal to the growth were filled with organizing thrombus.

Discussion. Pulmonary hypertension from neoplastic obstruction of the pulmonary arteries is uncommon, and this is explained by the limited duration of the patient's illness once the growth has reached the lungs. It is seldom too that the intra-arterial growth which has caused the hypertension has resulted from its extension from an adjoining focus in the lung. Such extension is a mark of its high malignancy which does not allow time for the arterial obstruction to become so diffuse as to cause pulmonary hypertension. It is usual also for such a penetrating growth to produce fatal hæmorrhage following the arterial invasion as in the case reported by Werner (1941).

Although in Case 6 the neoplasm had spread from the lung into the pulmonary arteries, such extension was limited and was considered to be a terminal event in a patient whose pulmonary hypertension had been established earlier by intimal proliferation formed in association with medial hypoplasia and with emphysema. The circumstances in which neoplasia are directly responsible for the establishment of pulmonary hypertension are illustrated by Case 7, in whom embolic growth was propagated in continuity within the ramifications of the pulmonary arteries, but its malignancy was sufficiently subdued to allow time for pulmonary hypertension to develop. 


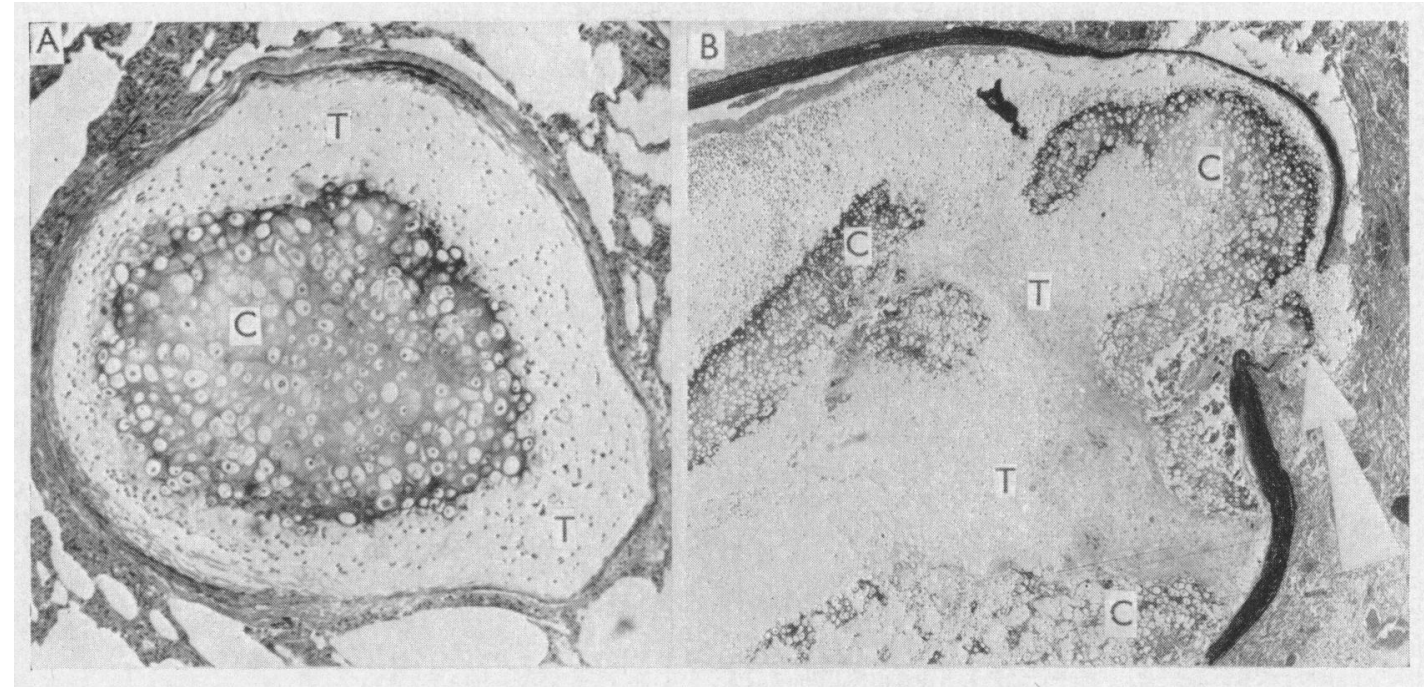

FIG. 19.--Pulmonary hypertension from pulmonary growth embolism. (A) Pulmonary artery $(\times 60)$ filled with chondrosarcoma $(\mathrm{C})$ at the centre and organizing thrombus $(\mathrm{T})$ at the periphery. (B) Pulmonary artery $(\times 20)$ filled with organizing thrombus $(T)$ and chondrosarcoma $(C)$, which at one point (arrow) has broken through the arterial wall. Case 7.

\section{SCLERODERMA}

Case 8. A man, aged 30, noticed that his fingers became numb and discoloured while bathing in the sea. A year later the hands and feet became swollen, and when he developed pain in the chest he was found to have pyrexia, pericardial friction sound, some degree of enlargement of the heart, infective polyarthritis, and a raised sedimentation rate. He was treated with penicillin, but without benefit to his joints or abatement of pyrexia which ranged from $99^{\circ}$ to $103^{\circ} \mathrm{F}$. The blood count was normal and showed neither leucocytosis nor eosinophilia. The blood culture was negative. The urine contained a small amount of albumen. He improved a little, but his condition again deteriorated during the next two months. A slight irregular pyrexia continued. There was limited movement of the spine, diffuse thickening of subcutaneous tissue of hands, fingers, feet and toes, with a slate-grey discoloration of the skin in these regions, and over the lower spine and buttocks. There was no cyanosis. The pulse was small and rapid, with a rate varying from 100 to 230 a minute. The blood pressure was $125 / 80$. The auricular wave of the jugular pulse was prominent, and pulsation over the right ventricle was increased. In the pulmonary area a sound in early systole was followed by a systolic murmur, and there was close splitting of the second heart sound whose pulmonary component was accentuated. A triple heart rhythm due to addition of the third heart sound was heard at the lower end of the sternum. The cardiogram showed right auricular and ventricular preponderance (Fig. 16). On cardioscopy there was enlargement of the right atrium, right ventricle, left ventricle, main pulmonary artery, and its primary branches which showed increased pulsation (Fig. 17). Biopsy of skin from the left forearm was not informative. There was no excess of 17-ketosteroid in the urine. He was given intramuscular injections of ACTH for a fortnight (1200 mg. in all), but this was discontinued with the advent of fluid retention. He felt better within a week and was allowed to go home, but was re-admitted five weeks later because of abdominal pain, diarrhœa, breathlessness, and swelling of the ankes. Heart failure signs had increased with a very high venous pressure and great distension of liver. There was now gross albuminuria. The blood pressure continued to be normal. He was given digitalis and both fluid and salt intake was restricted. Severe vomiting and diarrhœa set in. His blood urea was raised (51 mg. per $100 \mathrm{ml}$.) and convulsions set in. The retinae showed papillœdema, hæmorrhage and exudate. The blood pressure rose to $180 / 120$ and four days later to $210 / 150$, and remained high until his death three weeks later.

Necropsy findings. The heart weighed $781 \mathrm{~g} .\left(27 \frac{1}{2} \mathrm{oz}\right.$.). There was severe hypertrophy of the left ventricle without dilatation, and moderate hypertrophy and dilatation of the right ventricle. There was both recent and old pericarditis. The various organs showed the customary changes of heart failure.

Microscopy showed widespread arterial and arteriolar lesions in the skin, lungs, kidneys, gall bladder, intestine, and pancreas, but not in the suprarenals. The changes were severe and had caused such obstruction of the affected arteries and arterioles as to diminish or even occlude these vessels. The intra-arterial proliferative tissue consisted of a sparsely nucleated clear material. The media of the muscular arteries remained undisturbed, and the internal and external elastic layers were normally disposed (Fig. 20).

Discussion. In local scleroderma or morphœa the skin alone is diseased, but in its generalized form the pathological process involves muscle and blood vessels in addition to connective tissue. Matsui (1924), reporting on the clinical and pathological findings in six patients, particularly emphasized the vascular lesions that might occur in different localities, and Bevans (1945) discussed 
two cases where generalized scleroderma, endocardial and myocardial fibrosis, pulmonary fibrosis, and severe vascular lesions, were present in addition to the usual skin changes. She stated that the severity of the changes in the muscle bore no direct relationship to the extent of the vascular lesions. Dowling (1955) stated that clinical signs in the lungs in dermatomyositis varied from moderate shortness of breath to severe pulmonary hypertension. Christianson et al. (1956), reviewing unusual

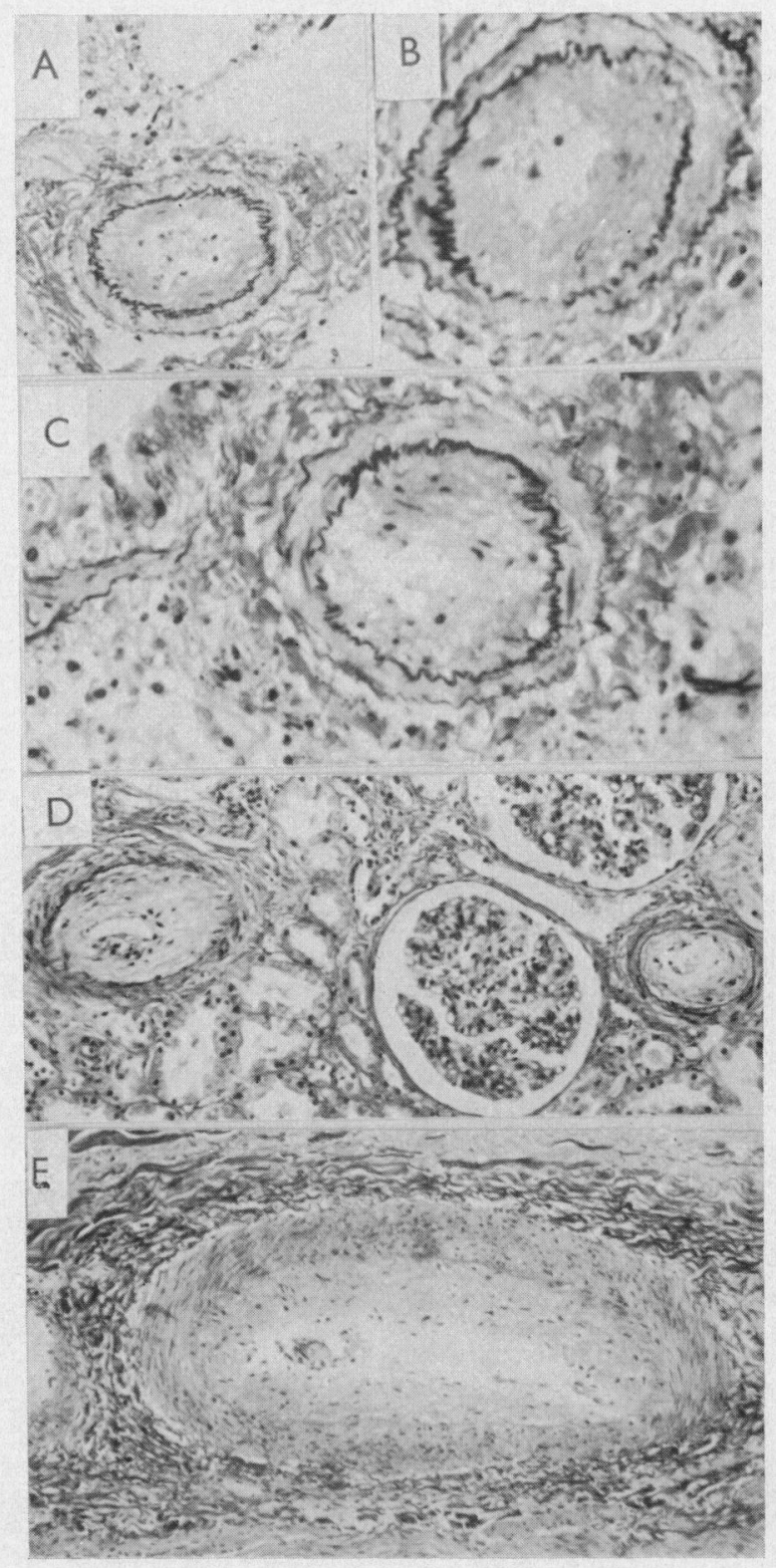

FIG. 20.-Pulmonary and systemic hypertension from scleroderma. The peculiar tissue of scleroderma almost completely fills the pulmonary arteries in (A) $(\times 145),(B)(\times 300)$, and $(C)(\times 250)$, the renal arteries in (D) $(\times 95)$, and an artery to the gall bladder in (E) $(\times 90)$. Case 8 .

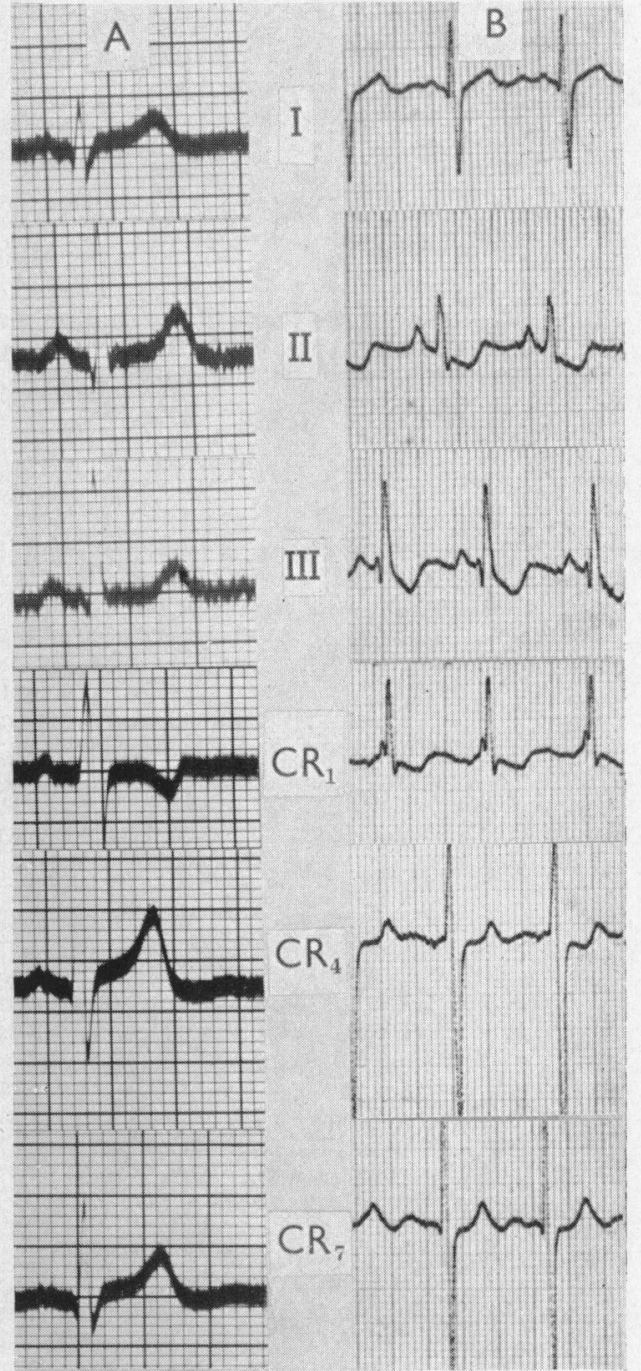

FIG. 21.-Pulmonary hypertension from anthracosis. Electrocardiogram in (A) is normal. In (B), which was recorded six years later, it shows right ventricular preponderance. Case 9. 
features and complications in 270 cases of dermatomyositis, did not mention pulmonary hypertension as one of them. Coolidge (1957) examined the electrocardiogram in 27 patients with dermatomyositis and found it normal in 19 , while the changes were only slight in the remaining 8 ; in none was there evidence of right ventricular preponderance. Talbot et al. (1939) reported a case in which all the viscera showed slight to moderate vascular changes, but the brunt had fallen on the renal arteries, where the proliferative process was well seen as a subintimal, sparsely nucleated, palely basophilic, and mucinous material having the appearance of Wharton's jelly. The internal elastic lamina was intact, and the lumen of the affected vessels was often a slit-like orifice as a result of the intimal thickening. The weight of the heart was $240 \mathrm{~g}$. In a woman aged 26, reported by Lewis (1940), the same intimal thickening was present in arteries to the fingers of the right hand and in arterioles of the kidney. During life the blood pressure rose from 140/95 to 205/145 and the blood urea was $225 \mathrm{mg}$. per $100 \mathrm{ml}$. The weight of the heart was $270 \mathrm{~g}$. No mention was made of the pulmonary arteries.

In the case reported here although the specific intra-arterial proliferation was present in most of the viscera, the material changes had taken place in the pulmonary and renal arteries, producing respectively pulmonary and systemic hypertension (holo-hypertension). A most remarkable finding was the great hypertrophy of the left ventricle, presumably reflecting a state of hypertension, although the blood pressure was only raised during the month preceding death. It is likely that the existence of pulmonary hypertension limited the rise of the systemic blood pressure until the last phase of the illness. Remarkable also in the electrocardiogram was the predominance of right ventricular preponderance over left, in the presence of such impressive hypertrophy of the left ventricle. The finding of such left ventricular hypertrophy, presumably the result of renal ischæmia, in the absence of a raised systemic blood pressure except for three weeks before the patient's death, suggests that in systemic hypertension, the hypertrophied left ventricle may arise directly from renal ischæmia, and may not be the direct effect of the associated raised blood pressure. This explains why in patients exhibiting the innocent clinical state of systemic hypertonia, the blood pressure value may reach impressive heights and yet the left ventricle does not enlarge.

The investigation, together with perusal of reported cases, would appear to establish that it is unusual for the heart to be affected in scleroderma and in dermatomyositis. When it is involved, it suffers in one of three ways, either from myocardial fibrosis, from pulmonary hypertension that follows infiltration of the pulmonary arteries by material peculiar to the disease, or from systemic hypertension that follows renal ischæmia caused by invasion of the renal arteries by the same specific material.

\section{Pulmonary Anthracosis}

Case 9. A coal-miner, aged 51, had worked underground for 23 years, and had been breathless for 16 years. He was also troubled with a cough and the expectoration of black sputum, while latterly a fairly severe hæmoptysis had set in. He was liable to recurrent attacks of bronchitis. The pulse and blood pressure were natural, and at the start of the illness, examination of the heart found no abnormal signs. The cardiogram (Fig. 21A) was a physiological tracing, while radiological examination of the chest showed no enlargement of the heart, but shadows consistent with fibrosis of the lungs were present, particularly on the left side (Fig. 22A). Gradually the clinical signs of pulmonary hypertension set in and right ventricular preponderance appeared in the cardiogram (Fig. 21B). Great extension of the pulmonary shadows had also taken place (Fig. 22B), and heart failure signs progressed.

Necropsy findings. The heart weighed $494 \mathrm{~g}$. There was great hypertrophy of the right ventricle (Fig. 14) which weighed $227 \mathrm{~g}$. compared with a left ventricle of $169 \mathrm{~g}$. A pulmonary arteriogram showed pruning of small and several larger pulmonary arteries. Both lungs showed large areas of dust fibrosis with patches of compensatory emphysema.

Histological examination showed invasion of pulmonary arteries by dust-bearing fibrotic tissue which along with thrombosis, had caused widespread arterial occlusion (Fig. 23).

Discussion. Among 100 patients with heart failure and normal rhythm reported by Parkinson and Clark-Kennedy (1925), 19 had enlargement of the right atrium and ventricle associated with pulmonary emphysema. In these they described hypertrophy of the pulmonary artery and its 
branches with intimal proliferation, which they thought had caused a persistent rise in the pulmonary arterial pressure. In one of their patients there was obliterative endarteritis in an anthracotic nodule.

Gough (1946) has made valuable contributions to the pathology of anthracosis, and while working in his department, Wells (1954) examined the pulmonary arteries in 388 necropsies on coalminers and described the histological changes under the three main heads of simple pneumoconiosis,

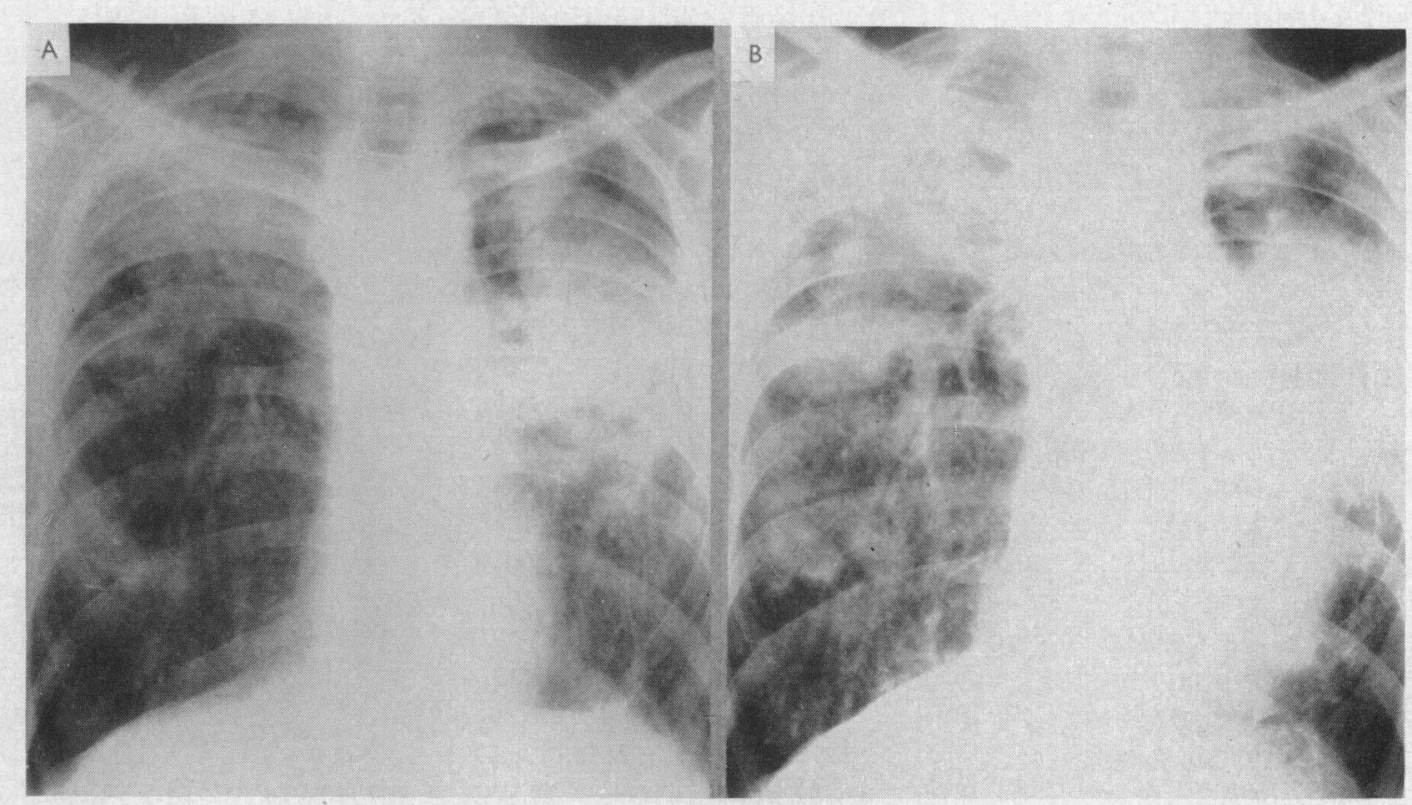

Fig. 22.-Pulmonary hypertension from anthracosis. No enlargement of the heart in (A) at the time when the first cardiogram (Fig. 21A) was recorded. Moderate enlargement of the heart and pulmonary artery in (B), six years later when second cardiogram (Fig. 21B) was recorded. Much greater pulmonary fibrosis in (B) than in (A). Case 9.
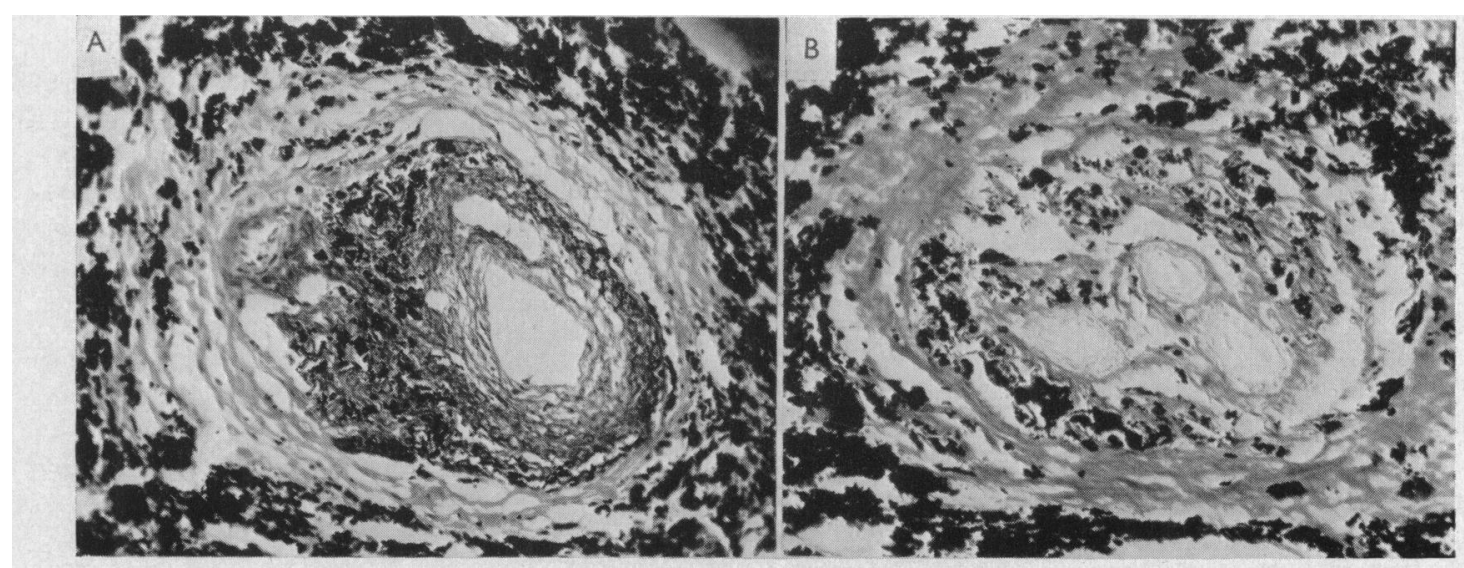

Fig. 23.-Pulmonary hypertension from anthracosis. (A) Particles of coal dust mingled with organizing thrombus severely restricting lumen of pulmonary artery $(280 \mu)$. (B) Similar changes with recanalization of pulmonary artery $(150 \mu)$. Case 9 . 
massive pneumoconiosis, and pneumoconiosis with tuberculosis. In the fibrotic areas in cases with massive pneumoconiosis there were both destructive and obstructive changes, involving both the small and medium-sized pulmonary arteries. The adjacent fibrotic process had eroded the walls and caused ulceration of the intima. He found thrombosis of considerable age occupying the main pulmonary arterial branches whenever the lobes that they supplied were the seat of severe fibrosis. He considered that such thrombosis had formed in situ and was not the result of embolism, and that the thrombosis first occurred in an arteriole near the growing fibrotic mass and extended proximally by reason of the stasis in the main vessel supplying that area. Thereafter, organization of the thrombus with recanalization takes place in the vessels close to the massive fibrotic lesions. Wells considered that the over-all loss of vessels from this process, and to a lesser extent by emphysema, was sufficient to cause pulmonary hypertension. James and Thomas (1956) were able to confirm these findings when they investigated cardiac hypertrophy in coalworkers' pneumoconiosis. Thus, marked right ventricular hypertrophy, recognized from the thickness of the right ventricular wall and often detectable during life in the electrocardiogram, was present in 57 per cent of those with massive fibrosis, but only in 17 per cent of the cases of simple pneumoconiosis. They established a direct relationship between the degree of enlargement and the extent to which arteriolar stenosis had restricted the pulmonary vascular bed.

\section{Pulmonary Asbestosis}

Case 10. A woman, aged 51, was first seen five years before, because of the recent onset of shortness of breath on walking up-hill. There was no cough and no voiding of sputum. Auscultation of the chest found moist sounds at both lung bases, but there was no dullness on percussion. Radiological examination of the chest showed shadowing at both hila. Between the ages of 18 and 29 she had worked in an asbestos factory. During five years before her death, breathlessness increased, but cough and hæmoptysis remained absent. Sputum was also absent or scanty, but when a specimen was examined it was found to contain asbestos bodies. There was no evidence of tuberculosis. The venous pulse in the neck was prominent and so also was the pulmonary second sound. There were no murmurs.

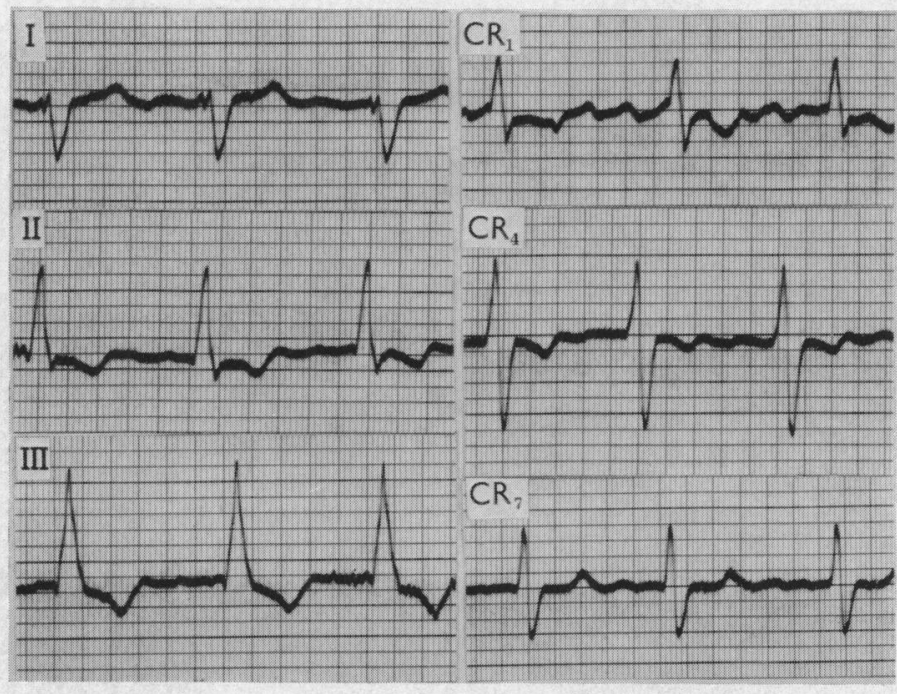

Fig. 24.-Pulmonary hypertension from asbestosis. Electrocardiogram shows atrial fibrillation and right heart preponderance with wide QRS complexes. Case 10.

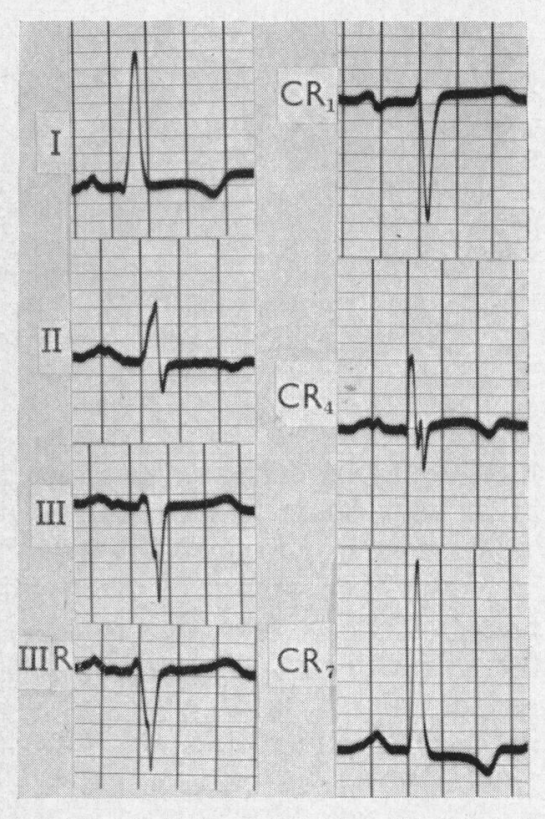

FIG. 25.-Pulmonary and systemic hypertension. Electrocardiogram shows left ventricular preponderance. Case 11. 
Latterly auricular filbrillation set in. The cardiogram showed right ventricular preponderance in addition to the arrhythmia (Fig. 24). Cardioscopy showed some enlargement of the right ventricle and shadowing of the lung parenchyma especially in the hilar regions (Fig. 26). She deteriorated rapidly and ultimately died suddenly.

Necropsy findings. The customary changes of heart failure were found in the viscera. There was moderate hypertrophy of the right ventricle which showed much dilatation. The heart weighed $387 \mathrm{~g}$. (13 oz.) and the body weight was only $46 \mathrm{~kg}$. (101 lb.). The lungs showed diffuse fibrosis which in places was dense.

Microscopical examination confirmed the severity of fibrosis which was widely distributed throughout both lungs and associated with numerous asbestos bodies. The larger pulmonary arteries were lined with a deep layer of organizing thrombus, and a similar change in the smaller arteries had severely reduced the bore of the lumen; this central canalization of thrombosed vessels appeared to be a long-standing change. In places such canalization was absent when the thrombus completely occluded the artery. These widespread changes were closely associated with the areas of severe fibrosis of the parenchyma (Fig. 29).

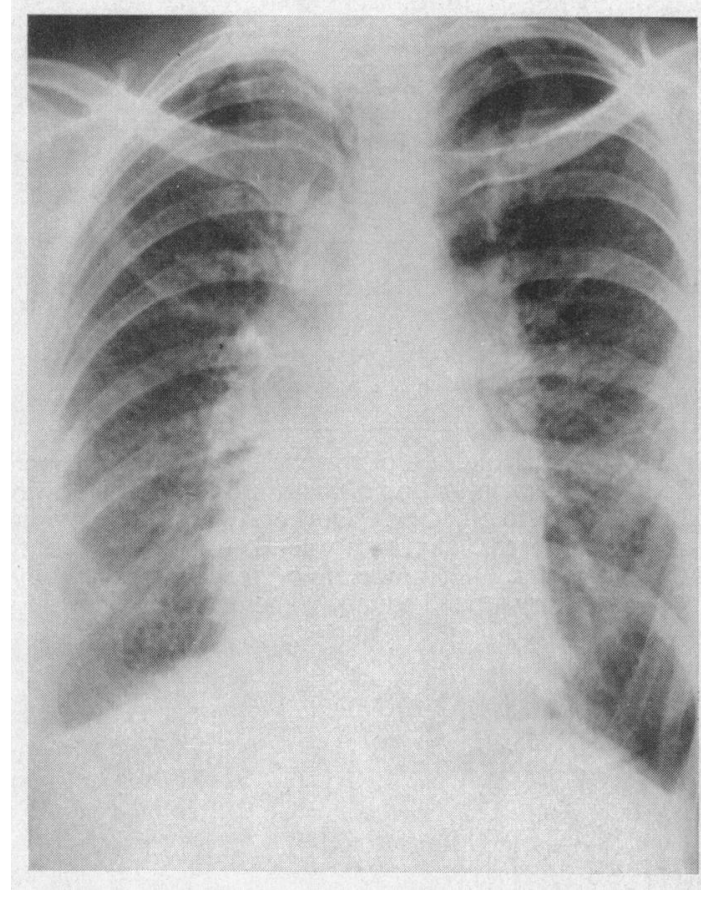

FIG. 26.-Pulmonary hypertension from asbestosis. Moderate enlargement of the right heart with dense shadows in hila. Case 10.

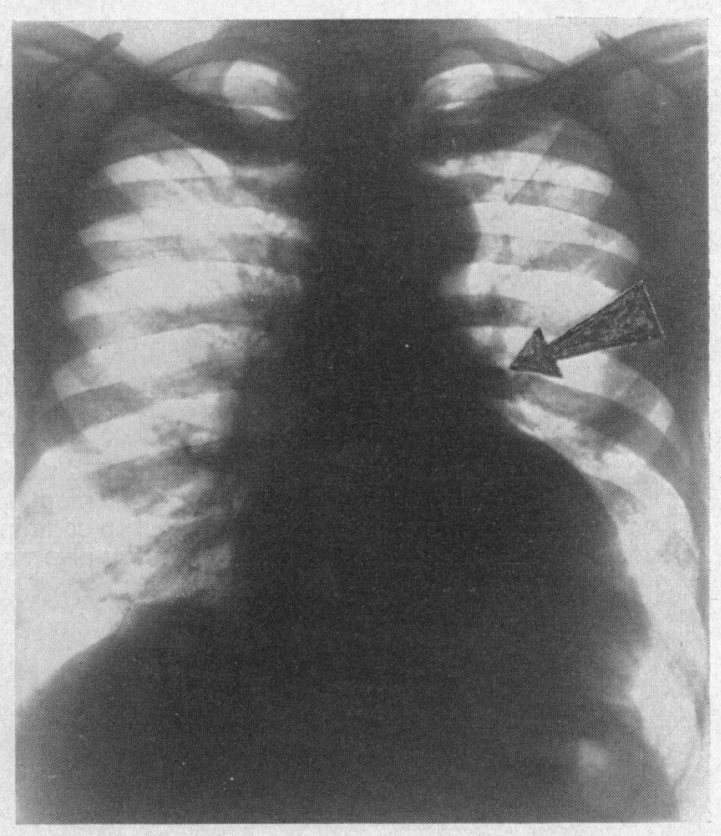

FIG. 27.-Pulmonary and systemic hypertension. Great enlargement of the left ventricle with prominence of aortic knuckle. Considerable distension of pulmonary artery (arrow). Pulmonary congestion. Case 11 .

Discussion. The mechanism whereby pulmonary hypertension forms in pulmonary asbestosis is the same as in anthracosis. It consists of thrombotic occlusion of the pulmonary arteries in regions heavily affected by fibrosis of the parenchyma. The arterial thrombosis follows constriction and actual penetration of the arterial wall by the fibrotic process. When the condition has been present for some time, recanalization of the occluded vessel takes place, and the residual calibre of the affected artery is severely reduced. In other vessels such recanalization does not take place, and in time the artery may be so disorganized as to become a ghost-like representation of itself. Pulmonary hypertension, therefore, only takes place when fibrosis is a prominent feature of the illness, for its development depends directly on the extent to which the pulmonary arterial bed is depleted by the fibrotic process in this characteristic way.

The clinical course of pulmonary asbestosis remains relatively benign, therefore, until massive fibrosis forms, bringing in its train occlusion of arteries sufficient to produce pulmonary hypertension and heart failure. 


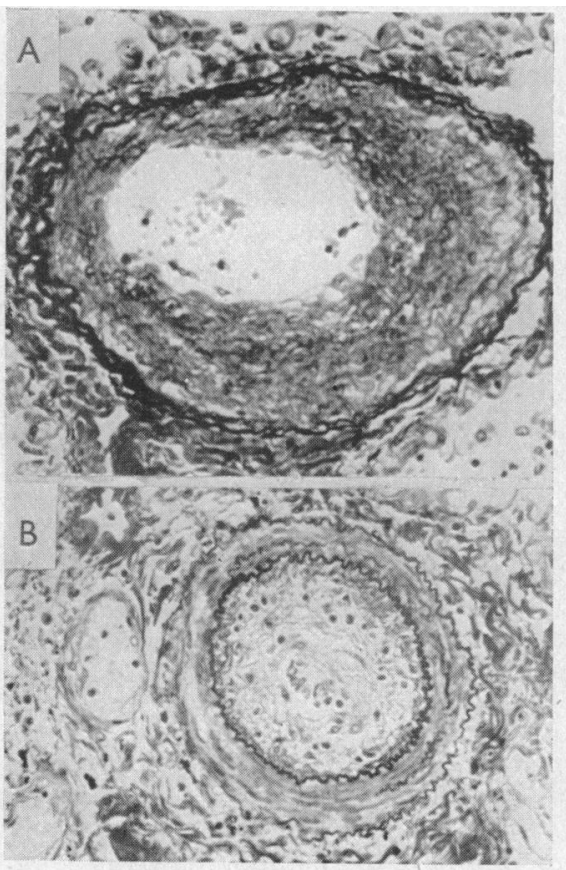

Fig. 28.-Myxoma of left atrium. (A) Partial obliteration of pulmonary vein $(210 \mu)$ by organized thrombus. (B) Almost complete obliteration of muscular artery $(170 \mu)$, whose wall is intact, by organized thrombus. Case 4.

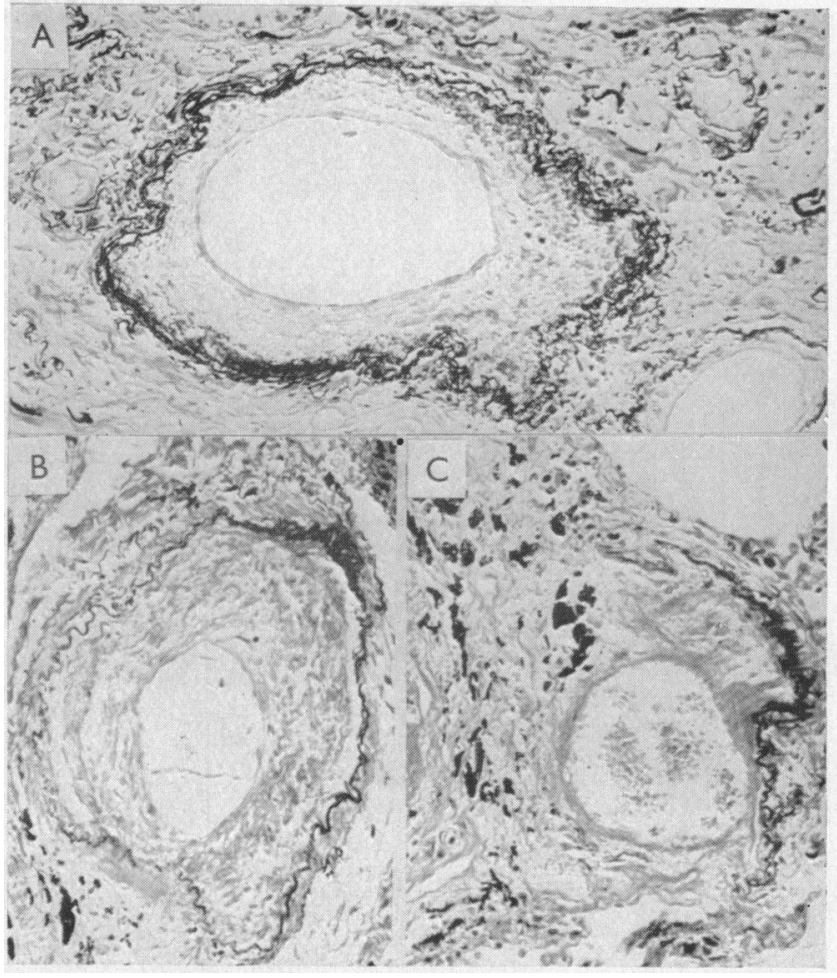

FIG. 29.-Pulmonary hypertension from asbestosis. (A) Moderate restriction of lumen of pulmonary artery $(286 \mu)$ by organized thrombus. (B) Canalised thrombus in greatly disorganized pulmonary artery $(210 \mu)$. (C) Completely disorganized pulmonary artery $(210 \mu)$ with remnant elastic layer on right and lumen surrounded by fibrosed thrombus containing carbon granules. Case 10.

\section{HOLO-HYPERTENSION}

Case 11. A man, aged 47, began to notice that he was short of breath some nine years previously, although he was not handicapped by this until two years before. Since then, breathlessness increased and frequent attacks of cardiac asthma had occurred by day as well as at night. He had not complained of pain. When admitted to hospital he was gasping for breath. The pulse was natural and the blood pressure was 140/120. The brachial arteries were contracted, as also were the retinal arterioles. The apex beat was displaced outwards and was forcible. The pulmonary second sound was rather loud, and triple heart rhythm from addition of the third heart sound was present. The urine was clear and the blood urea was not raised. The cardiogram (Fig. 25) showed left ventricular preponderance and no evidence of right atrial or ventricular duress. Radiological examination of the heart showed great general enlargement and especially of the left ventricle, with pulmonary congestion. The aorta was slightly dilated and there was some distension of the pulmonary artery (Fig. 27).

The following blood pressure values are samples recorded during nine months before his death: 150/100, 135/105, $140 / 110,135 / 105,130 / 100,145 / 115$, and 125/85. Just before his death, figures like 140/105, 140/115, and 145/115, were obtained.

For a time he improved from the orthodox form of treatment of heart failure, but his condition gradually deteriorated, and he died two years after the onset of noticeable breathlessness.

Necropsy findings. The heart weighed $728 \mathrm{~g}$. $(26 \mathrm{oz}$.), and there was gross hypertrophy $(2 \cdot 2 \mathrm{~cm}$. thick) with slight dilatation of the left ventricle. Moderate hypertrophy $(0.8 \mathrm{~cm}$. thick) of the right ventricle. Dilatation without hypertrophy of both right and left atria. The heart valves were normal and the coronary arteries widely patent on inspection. A small thrombus in pulmonary artery to the right upper lobe had not caused infarction. Other viscera showed the customary changes of heart failure.

Histological examination of both pulmonary and renal arteries showed identical changes, namely deficiencies of their walls from hypoplasia, and sometimes aplasia, of the media, with associated intimal proliferation which had partly or wholly occluded the vessels. One branch of a coronary artery was similarly affected (Fig. 30). 
FIG. 30.-Pulmonary and systemic hypertension. (A) Coronary artery $(430 \mu)$, showing hypoplasia of its media on the left, and great restriction of its lumen by intimal proliferation. (B) Aplasia of the media of a renal artery $(1.4 \mathrm{~mm}$.) involving two-fifths of its circumference, with almost complete obliteration of its lumen by intimal proliferation. (C) Aplasia of pulmonary artery $(210 \mu)$ in its whole circumference with intimal proliferation causing severe restriction of its lumen. (D) Aplasia of renal artery $(270 \mu)$ involving two-thirds of its circumference, and associated intimal proliferation. (E) Severe restriction of pulmonary artery $(210 \mu)$ by intimal proliferation and hypoplasia of its media. (F) Hypoplasia and aplasia of wall of pulmonary artery in its upper portion, and severe intimal proliferation of this and of its branch below. Case 11 .

Discussion. In that systemic hypertension is a common illness and pulmonary hypertension is not rare, it causes no surprise to find both conditions simultaneously in the one patient at times. This combined or generalized hypertension (holo-hypertension) is present when occlusion affects both the pulmonary and renal arteries. In most instances, intimal proliferation forming alongside medial hypoplasia, provides the occlusive lesion as in Case 11, but rarely it may result from some specific material as in Case 8 which was an example of scleroderma.

Holo-hypertension assumes greatest importance on account of the difficulty it gives rise to in diagnosis. The physical signs are modified in accordance with the relative severity of either the systemic or pulmonary hypertension, and the resulting preponderance of either left or right ventricular hypertrophy.

Thus, if the effects of systemic hypertension are uppermost, the cardiogram will show left ventricular preponderance, great prominence of the left ventricle and the aortic knuckle on radiological examination, as in Case 11. In this event, signs of remaining pulmonary hypertensive effects should be sought, and these might include accentuation of the pulmonary second sound, enlargement of the pulmonary artery, and some cardiographic signs of right atrial and ventricular enlargement. 
If the effects of pulmonary hypertension are uppermost, the cardiogram will show right ventricular preponderance, and the expected raised systemic blood pressure is subdued as in Case 8. In this event, evidence of remaining systemic hypertensive effects should be sought and which might include a maintained raised diastolic pressure in spite of the lowered systolic reading, considerable enlargement of the left ventricle on radiological examination, and some cardiographic signs of left ventricular enlargement.

\section{The Mechanism of Pulmonary Hypertension}

As a preliminary to a discussion of the ætiology of pulmonary hypertension it is necessary to adhere to the precise definition of the condition as a state where a persistent rise in the pulmonary arterial pressure has been sufficient to cause hypertrophy, and ultimately failure, of the right ventricle, and where the electrocardiogram shows right ventricular preponderance.

The establishment of pulmonary hypertension is decided by obstruction within the pulmonary arteries, but the nature of this obstruction varies. The present paper describes some of the less common forms, and the way in which these contribute to a decision on the sequel of events that lead to the development of the occlusive lesion.

The Nature of the Arterial Obstruction. The arterial block in recurring or shower embolism from systemic vein thrombosis, as happened in Cases 1 and 2, is composed of thrombus. Obstruction by thrombus is also a prominent feature when the fibrotic lesion formed in pneumoconiosis penetrates the arterial wall to produce pulmonary hypertension as in Cases 9 and 10. In each of these four cases histological examination showed no hypoplasia of the media in the obstructed arteries.

The emboli that caused the arterial obstruction in Case 7 were composed wholly of neoplastic tissue. For such a neoplasm to produce pulmonary hypertension it is necessary that the emboli should be multiple and capable of intravascular proliferation in continuity without any great tendency to invade the vessel wall, manifesting a relatively low grade of malignancy. In Case 6, although carcinomatous cells were found in the tissue that obstructed the pulmonary arteries, it had been an immaterial and terminal invasion of existing intimal proliferation in a patient whose pulmonary hypertension had developed in the course of emphysema.

No example of parasitic embolism in Bilharzia infestation was met with, although it is not a rare cause of pulmonary hypertension in some countries.

In Case 8 the specific tissue of scleroderma had filled the pulmonary arteries whose media was intact.

Intimal proliferation is the name applied to the tissue that most commonly occludes the lesser pulmonary arteries and arterioles in pulmonary hypertension. Histologically it is distinguished with difficulty from organized thrombus, but its more generalized distribution and the absence of any source of embolism usually makes the differentiation possible. Although it has sometimes been named endarteritis fibrosa, suggesting an inflammatory basis, the term intimal proliferation is preferred since it allows the conception that this reactive material is the product of a localized reparative process.

The Relation of Intimal Proliferation to Pulmonary Hypertension. In the large majority of patients with pulmonary hypertension, histological examination will reveal intimal proliferation as the cause of the arterial block. This proved to be the case when pulmonary hypertension was a lone finding (Gilmour and Evans, 1946; Evans et al., 1957), when it was associated with emphysema (Evans, 1951) or with mitral stenosis (Evans and Short, 1957), and again in the presence of cardiac shunts like atrial septal defect, ventricular septal defect, patent ductus arteriosus, and aortopulmonary fistula (Evans and Short, 1958).

Since its common association with pulmonary hypertension has been proved, there is need to decide whether intimal proliferation precedes or succeeds the hypertension. The findings in the less common varieties of pulmonary hypertension which are recorded here bring light to this question.

Thus, in Cases 1 and 2, where the distribution of the arterial lesions along with the clinical 
findings confirmed that they were thrombotic in nature and arising as embolism from veins of the lower extremities, intimal proliferation was absent, and the media of the pulmonary muscular arteries was intact. Similarly, in Cases 6,8,9, and 10, arterial obstruction was caused by material other than intimal proliferation. Moreover, in Case 3 with strangulation of the pulmonary veins, and in Cases 4 and 5 where a myxoma filled the left atrium, a considerable rise of the pulmonary arterial pressure, or pulmonary hypertonia, had been present for a long time, yet intimal proliferation had remained absent and true hypertension had not developed. The findings, therefore, in these three groups of cases testify to intimal proliferation being the prelude to, and not the outcome of, pulmonary hypertension.

Another constant feature of intimal proliferation has been its invariable association with segmental hypoplasia of the media of the pulmonary muscular arteries.

Arterial Medial Deficiencies. It was Gilmour and Evans (1946) who first described hypoplasia and aplasia of the media of the smaller pulmonary muscular arteries in a patient with so-called primary pulmonary hypertension. Later, Evans (1951) was so impressed with the frequency of the same change in other instances that he described them under the title of congenital pulmonary hypertension.

As in the case of intimal proliferation, medial deficiencies likewise were not found in significant numbers in Cases 1, 2, 6, 8, 9, and 10, where pulmonary hypertension had followed obstructive arterial lesions other than intimal proliferation, nor were they present in Cases 3, 4, and 5 where true pulmonary hypertension had not ensued in spite of the persistence for some time of an impressive rise of the pulmonary arterial pressure.

These findings support the conclusion that in the absence of segmental deficiencies in the walls of pulmonary muscular arteries from medial hypoplasia, intimal proliferation leading to arterial obstruction with subsequent pulmonary hypertension does not take place.

A recent investigation (Evans, 1959) has shown a high incidence of polythelia or accessory nipples among patients with pulmonary hypertension. The incidence was 44 per cent among such patients compared with 7 per cent among patients with pulmonary hypertonia only, and 5 per cent among healthy subjects. Since polythelia is an atavistic phenomenon, its high incidence in any clinical state, and in pulmonary hypertension in the present context, suggests for it a genetic or congenital origin. It is held here that medial deficiencies of the pulmonary muscular arteries, whose presence is conditional for the development of intimal proliferation and subsequent hypertension, arise from congenital medial hypoplasia.

\section{SUMmARY AND CONCLUSIONS}

The clinical and pathological findings are described in 11 patients whose pulmonary arterial pressure was raised from diverse causes and for some time before their death.

In three of these, two with myxoma of the left atrium and one with strangulation of the pulmonary veins by a granuloma, although the pulmonary arterial pressure was raised to impressive heights, the electrocardiogram showed evidence of right ventricular duress that was short of ventricular preponderance. These three patients have been included because they contribute to a better understanding of the mechanism of pulmonary hypertension.

The remaining eight patients suffered from pulmonary hypertension, defined as a condition where a persistent rise in the pulmonary arterial pressure has caused hypertrophy and failure of the right ventricle, with characteristic clinical, cardiographic, and radiological signs. These eight illustrate the less common forms of pulmonary hypertension, and include two with recurring pulmonary embolism, two with growth embolism, two with pneumoconiosis, one with scleroderma, and one with holo-hypertension.

Histological examination of the pulmonary vasculature in the 11 cases confirmed that pulmonary hypertension is the direct result of obstruction within the pulmonary artery.

In the less common forms of pulmonary hypertension, the arterial occlusion is caused by 
thrombus in the case of recurring pulmonary embolism, anthracosis, and asbestosis, by a specific tissue in scleroderma, and by parasitic ova in Bilharzia infestation.

In the more common examples of pulmonary hypertension, the arterial obstructive lesion is in the form of intimal proliferation associated with congenital hypoplasia of the media; these two changes, which were never found apart, precede rather than follow the hypertension.

In the presence of medial hypoplasia, the formation of intimal proliferation is hastened by any condition that raises the pulmonary arterial pressure as in mitral stenosis, congenital cardiac shunts, and emphysema; in solitary pulmonary hypertension, where the pulmonary arterial pressure is natural at the start, intimal proliferation gains its stimulus from the presence of innumerable medial deficiencies.

I am indebted to Dr. D. S. Short for pulmonary arteriograms in Cases 1, 2, and 9. I wish to thank several colleagues for so readily allowing me to include in this paper, patients in their care. Thus, I am indebted to Dr. Wallace Brigden for Case 3, Dr. C. L. Cope for Case 5 which is to be published separately by Dr. G. A. MacGregor and Dr. R. A. Cullen, Sir Alun Rowlands for Case 8, Dr. Arthur Thomas for Case 9, and Lord Evans for Case 11. I particularly wish to thank Dr. Dorothy Russell of the Bernhard Baron Institute of Pathology, London Hospital, for placing at my disposal the findings at necropsy in eight of the cases and for her helpful advice.

\section{REFERENCES}

Bevans, M. (1945). Amer. J. Path., 21, 25.

Christianson, H. B., Brunsting, L. A., and Perry, H. O. (1956). A.M.A. Arch. Dermat., 74, 581.

Coolidge, S. W. (1957). Amer. Heart J., 53, 754.

Dowling, G. B. (1955). Brit. J. Dermat., 67, 275.

Edwards, J. E., and Burchell, H. B. (1951). Arch. intern. Med., 87, 372.

Evans, W. (1951). Proc. Roy. Soc. Med., 44, 600.

- (1959). Brit. Heart J., 21, 130.

_- and Short, D. S. (1957). Brit. Heart J., 19, 457.

- - (1958). Brit. Heart J., 20, 529.

- - — - and Bedford, D. E. (1957). Brit. Heart J., 19, 93.

Gilmour, J. R., and Evans, W. (1946). J. Path. Bact., 58, 687.

Gough, J. (1946). Lancet, 1, 462.

James, W. R. L., and Thomas, A. J. (1956). Brit. J. Indust. Med., 13, 24.

Kunkel, W. M., Clagett, O. T., and McDonald, J. R. (1954). J. Thor. Surg., 27, 565.

Lewis, T. (1940). Brit. J. Dermat., 52, 233.

Matsui, S. (1924). Mitt. med. Iakuet. Univ. Tokyo, 31, 55.

Parkinson, J., and Clark-Kennedy, A. E. (1925). Quar. J. Med., 19, 113.

Talbot, J. H., Gall, E. A., Consolazio, W. V., and Coombs, F. S. (1939). Arch. intern. Med., 63, 476.

Wells, A. L. (1954). J. Path. Bact., 68, 573.

Werner, W. I. (1941). J. Thor. Surg., 10, 658. 